Review

\title{
Solar Thermal Energy Stills for Desalination: A Review of Designs, Operational Parameters and Material Advances
}

Wisut Chamsa-ard ${ }^{1,+}$, Derek Fawcett ${ }^{1,+}$, Chun Che Fung ${ }^{2,+}$, Gerrard Poinern ${ }^{1,{ }^{+*}}$

1. Murdoch Applied Nanotechnology Research Group, Department of Physics, Energy Studies and Nanotechnology; E-Mails: wisut sert@hotmail.com; fawcett@southwest.com.au; g.poinern@murdoch.edu.au

2. School of Engineering and Energy, Murdoch University, Murdoch, Western Australia 6150, Australia; E-Mail: L.Fung@murdoch.edu.au

† These authors contributed equally to this work.

* Correspondence: Gerrard Poinern; E-Mail: g.poinern@murdoch.edu.au

Academic Editor: Joaquin Alonso-Montesinos

Special Issue: Photovoltaic Solar Systems and Solar Thermal Plants

Journal of Energy and Power Technology

2020 , volume 2 , issue 4

doi:10.21926/jept.2004018
Received: September 28, 2020

Accepted: December 14, 2020

Published: December 29, 2020

\begin{abstract}
The demand for high-quality freshwater is increasing due to global population growth, intensifying agricultural practices and expanding industrial development. Additionally, many global regions have low levels of rainfall which makes them arid and incapable of supporting large human populations or agriculture. Currently, large quantities of fossil fuels are used to generate the power needed to drive energy intensive desalination processes that deliver highquality freshwater to many of these regions. However, the use of fossil fuels has led to high greenhouse gas emissions, environmental degradation and global warming. Solar-thermal desalination is a low-cost, sustainable and eco-friendly strategy for producing high-quality freshwater without using energy derived from fossil fuels. However, in spite of recent developments to advance solar-thermal desalination, the most effective strategies for achieving higher performance levels still remains elusive. To tackle this problem, the present
\end{abstract}

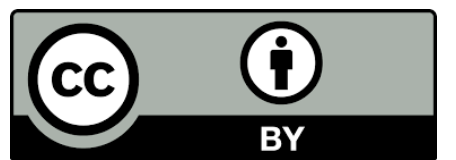

(C) 2020 by the author. This is an open access article distributed under the conditions of the Creative Commons by Attribution License, which permits unrestricted use, distribution, and reproduction in any medium or format, provided the original work is correctly cited. 
article reviews several solar-thermal still configurations, including materials, system design parameters, influencing factors and operational parameters. Moreover, recent material advances in plasmonic nanoparticle-based volumetric systems, nanomaterial enhanced phase change materials and interfacial solar evaporators are discussed. These new material advances can have the potential to significantly improve the conversion of light-to-heat, enhance vapor generation and promote greater water production rates.

\section{Keywords}

Solar-thermal, desalination, solar stills, nanomaterials, photothermal materials

\section{Introduction}

The demand for high quality water to supply an ever-growing global population and the decline of existing high quality water sources are creating serious challenges for humanity [1]. Furthermore, increasing global temperatures, growing green-house gas emissions and diminishing natural resources are also contributing to these global challenges [2]. Moreover, current agricultural practices involved in food production depend heavily on natural resources, ecosystems and water resources that are currently under stress, and in many parts of the world are in decline [3]. Additionally, increasing human urbanization, mining and industrialization have also contributed to the demand for high quality water. Because of these challenges and the need to limit global temperature rises (up to $2{ }^{\circ} \mathrm{C}$ with respect to pre-industrial levels) [4], international collaborative efforts are focusing on developing sustainable technologies for reducing global warming and producing alternative sources of high quality water. Crucially, finding new sources of high quality water is of particular importance, since current estimates indicate that around two thirds of the global population will lack sufficient quantities of high quality water by 2025 [5]. This situation is further exacerbated with many of these populations being located in hot and arid countries, or in countries where available water supplies cannot be used for drinking or farming due to salinity. Thus, global efforts have focused on strategies that can deliver high quality water sources to meet the needs of a predicted global population of 12.3 billion in 2100 [6, 7]. Current estimates indicate the annual global demand for water is increasing by $2 \%$, and consumption is expected to reach 6,900 Billion $\mathrm{m}^{3}$ in 2030 [8]. Unfortunately, the Earth's natural water cycle of 4,200 Billion $\mathrm{m}^{3}$ per year cannot meet this demand [9]. Thus, creating a shortfall of 2700 Billion $\mathrm{m}^{3}$. Currently, this shortfall is alleviated by the use of high-energy consuming desalination plants. Thus, establishing the close interdependent relationship between water and energy. Since the energy is needed to collect, desalinate and distribute water to end-users. At present there are around 18,000 desalination plants located in 150 countries producing over 38 billion $\mathrm{m}^{3}$ per year. Importantly, current estimates indicate this output will increase to around 54 billion $\mathrm{m}^{3}$ in 2030 [10].

The power needed to drive these energy-intensive desalination processes is derived from fossil fuels. Current estimates indicate that around 10,000 tons of oil are used annually to generate 1000 $\mathrm{m}^{3}$ of desalinated water each day [11]. Typical desalination processes include: 1) multi-stage flash (MSF); 2) multi-effect distillation (MED); 3) vapor compression (VC); 4) reverse osmosis (RO), and 5) electro-dialysis (ED) $[12,13]$. Besides producing high quality drinking water, desalination plants are 
currently discharging about 76 million tons of $\mathrm{CO}_{2}$ into the atmosphere each year. With current modelling predicting this discharge increasing to 218 million tons of $\mathrm{CO}_{2}$ per year by 2040 [14]. Moreover, brine discharges from desalination plants pollutes the marine environment and threatens aquatic life [15]. Because of the discharge of harmful by-products into the environment, recent research efforts have focused on alternative desalination processes capable of producing high quality water [16]. Thus, using renewable solar thermal energy offers an alternative long-term and sustainable desalination process for producing high quality water [17]. Moreover, most of the countries in need of new sources of high quality water are also located in global regions were large amounts of solar radiation are received annually. Crucially, studies have shown that around $1.8 \mathrm{x}$ $10^{14} \mathrm{~kW}$ of solar energy reach the Earth annually. With about $60 \%$ reaching the Earth's surface and the remaining $40 \%$ being reflected back into space by the atmosphere $[18,19]$. In fact, the hourly rate of solar radiation striking the Earth's surface is greater than the annual global consumption of energy produced from fossil fuels [20-22]. Thus, making solar radiation the largest source of sustainable and renewable energy. It is also the largest source of renewable energy which is collected, concentrated and transformed into other forms of usable energy. Therefore, harvesting solar thermal energy is considered a sustainable alternative to current fossil fuel-based and highenergy consuming desalination processes for converting saline water into high quality drinkable water [2, 23].

The present article is composed of three parts, with each part reviewing and discussing a specific aspect of solar thermal still design. The first part reviews the literature in the field and summarizes the variety of designs and configurations developed in recent years. The second part reviews the operating principles of solar stills, and recent research efforts to improve their efficiency and throughput. While the third part summarizes recent nanotechnology-based approaches for creating smart materials for integration into solar thermal applications. In particular, the use of nanometer scale materials in two new strategies, namely nanoparticle-enhanced vapor generation (volumetric) and floating solar receivers for increased vapor generation. Significantly, these two new strategies are capable of increasing solar to thermal energy conversion rates under the irradiance of one sun.

\section{Direct Desalination Using Solar Stills}

\subsection{Solar Still Concept}

The energy-intensive desalination processes mentioned above use very large amounts of energy derived from fossil fuels [24]. Alternatively, solar thermal desalination offers the advantages of simple design, construction, and low maintenance costs. Importantly, solar thermal desalination processes are eco-friendly and do not produce harmful greenhouse gas emissions [25]. At present, desalination using solar energy is accomplished by utilizing solar ponds, solar thermal collectors and solar photovoltaic/membrane systems [26-28]. The most direct and simplest technology for desalination uses solar thermal stills, where the conversion of solar energy to heat and the production of high quality water are achieved in the same equipment. The operation of a solar thermal still is straightforward. It typically consists of a basin is filled with saline water to a specific depth. The inner surfaces of the basin are blackened by a surface coating such as paint for absorbing the radiation. The basin is covered by an inclined transparent glass covering that promotes the transmission of solar energy. When the solar radiation enters the still it gets absorbed by the saline water and the basin coating. And with time, the water temperature and vapor pressure increase 
and as a result, the rising water vapor condenses on the underside surface of the inclined glass covering as seen in Figure 1. The condensed water then flows downwards along the glass covering towards a trough fitted along the entire length of the covering $[29,30]$. The collected water is a distilled solution, free of impurities and is suitable for drinking [31]. Thus, solar thermal stills directly produce high quality water without the need for energy derived from fossil fuels. On the other hand, water vaporization is a surface phenomenon and only water molecules present at the air-water interface can be evaporated into the vapor phase [32, 33]. In addition to the vapor being produced, there are also heat losses resulting from energy being transferred to the water volume below the air-water interface that are not involved in the evaporation process. These undesirable heat losses lead to low water basin temperatures, low water production rates, and lower system performance efficiencies. However, the advantages using solar thermal stills are: 1) their ability to produce several liters of high quality water per square meter per day; 2) they can be easily designed, fabricated and operated; 3) they don't need external energy to operate; 4) they don't generate harmful greenhouses gases; 5) initial investment costs are lower than other desalination technologies [14]; 6) they have working efficiencies ranging from 30 to $60 \%$ for operational periods as long as 20 years, and 7) compared to other desalination technologies, solar thermal stills are more economically viable for supplying high quality water to individual households and small communities [34-36]. In spite of these advantages, solar thermal stills are not widespread due to their relatively low water output compared to other desalination technologies. And as a result, recent research has focused on improving solar thermal still productivity [27, 37-39].

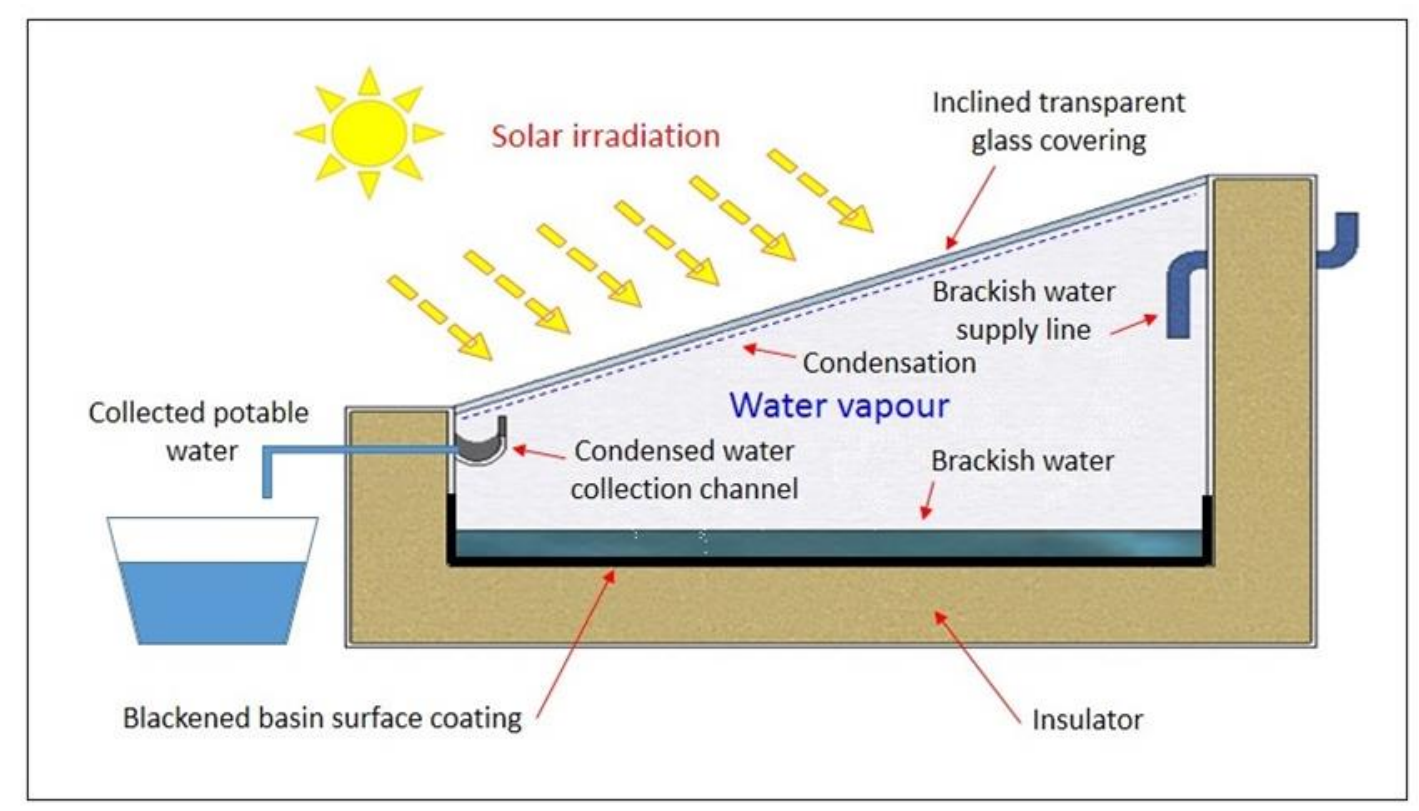

Figure 1 Concept of a typical passive solar still.

\subsection{Types of Solar Stills}

Research into developing methods for direct solar thermal desalination are broadly classified into two groups, namely single effect and multi-effect. Both groups can be further categorized into two sub-groups (passive or active) depending on the heat source used to evaporate the water within the still. Passive solar thermal stills are specifically designed to use only solar energy to generate internal 
heat within the still to drive the evaporation process. While active solar thermal stills not only use solar energy, but also use heat generated from external systems such as solar ponds, solar collectors and waste heat from nearby industries. The original solar thermal still design, as seen in Figure 1, is a passive single-effect system. During its operation water in the basin is heated by absorbing solar energy and evaporates. The resulting water vapor condenses on the underside of the transparent glazing. During this process large amounts of heat is lost from the still via the glazing. This heat loss limits the solar stills efficiency to between 30 and $40 \%$, while limiting its water production rate to around $6 \mathrm{l} / \mathrm{m}^{2} /$ day [40]. Because of the low efficiencies and low water productivities normally associated with the original solar still, recent research has focused on improving the original design and developing new types of stills $[28,41,42]$. The following section summarizes the development of various types of solar thermal stills designed to increase evaporation and condensation rates. Figure 2 presents a schematic representation of four solar thermal still designs that have been developed. While Table 1 at the end of this section presents a selection of performances for a variety of solar still configurations.

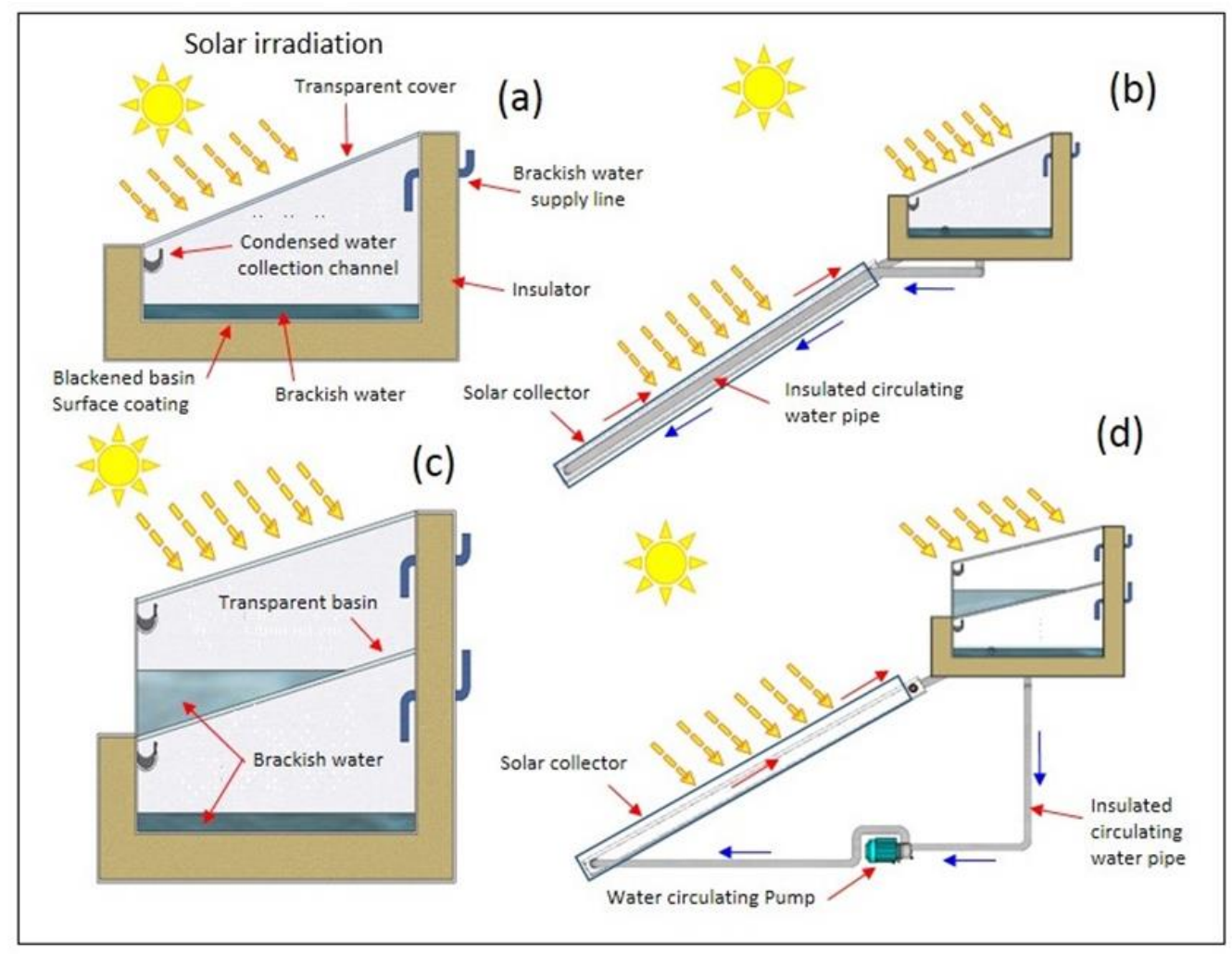

Figure 2 A schematic representation of (a) passive single effect solar still, (b) active single effect solar still coupled to a collector in the natural circulation mode, (c) passive multi effect solar still, and (d) active multi effect solar still coupled to a collector in the forced circulation mode.

\subsubsection{Single-effect Solar Thermal Stills}

2.2.1.1 Passive Systems. In terms of passive systems, several types of single-effect solar thermal stills have evolved over the years. Basin stills have evolved from the original solar thermal still concept [41]. In this configuration saline water is contained in a basin which is enclosed within an 
airtight still structure, see Figure 2 (a) and (c). Typically, in this type of design, a sloped transparent cover made of glass or plastic permits the transmission of solar irradiation. The entering solar radiation not only heats the water in the basin, but also heats the air above the water surface. As heating continues, water evaporates and saturates the air contained within the still. The resulting temperature difference between the cover and water surface generates circulating air currents. On meeting the cooler cover, the saturated air is cooled and pure water droplets condense on the cover. And due to gravity, the formed water droplets run down the cover and are collected by a channel that diverts the accumulating water to a storage tank. Studies into increasing basin still productivity has resulted in improvements of the basic design structure, using new materials and optimizing system parameters.

Several studies have examined using plastic covers instead of glass covers to enhance solar irradiation transmission [43]. Similarly, other studies have investigated the performance of several cover shapes like flat, hemispherical, partial spherical and bi-layer semi-spherical [44, 45]. Studies have also examined the slope of flat covers, with the slope being selected for maximum solar irradiation capture and optimal water production for the specific latitude location of the still [46]. A numbers of studies have also evaluated solar thermal still designs with cooling water flowing over their covers to increase their efficiency [47]. For example, study by Arun Kumar et al. has reported that cover cooling can increased still efficiency from 34 to $42 \%$ [44]. Interestingly, a comparative study between single and double basin solar stills with sloping flat covers discovered that single basins performed better in colder climates and double basins performed better in warm climates [48].

Studies have also shown the inclusion of internal and external reflectors, which are designed to introduce more solar radiation into the solar still, can significantly improve its performance. For instance, a study by Monowe et al. found that a portable thermal-electrical solar still fitted with an external reflector and an outside condenser could reach operational efficiencies of around 77\% [49]. Similarly, Tanaka's group found the daily water productivity of a basin type still fitted with internal and external reflectors could be increased by around 70\% [50]. Alternatively, the incorporation of fins and corrugations into basin floors have been found to improve performance. For example, compared to a conventional single slope basin still, under the same climate conditions, the performance of the same still fitted with either fins or corrugations showed productivity improvements of around $40 \%$ and $21 \%$ respectively [51].

Another enhancement feature that has been investigated for incorporation into the basin structure is heat storage materials. The advantage of these materials arises after sunset, when heat is released into the still to maintain the water evaporation cycle. Importantly, night time temperatures are lower, so there are greater temperature differences between the cover and basin. For instance, the incorporation of black granite gravel was found to increase productivity by around 17 to $20 \%$ when compared to a still without gravel [52]. Researchers have also found evaporation rates can be significantly increased by incorporating floating absorbers combined with wick materials to the basin water $[53,54]$. For instance, the incorporation of sponge cubes in basin water were not only found to increase evaporation rates, but also increased still productivity up to $273 \%$ when compared to a similar still without sponge cubes and operating under the same conditions [55].

Wick-based solar thermal stills are another passive method for generating high quality water from saline sources. The difference between a wick-based solar stills and basin stills is that saline 
water slowly flows through a thin porous material, commonly called the wick. During day light hours the porous wick is always wet due to capillary action. Importantly, the lower heat capacity of the water contained within the wick means there is less time for evaporation to take place [56]. Thus, efficiency levels are typically between 16 and $50 \%$ greater than traditional basin solar stills [57]. This enhancement in efficiency results from two important parameters not present in traditional basin solar thermal stills. The first parameter is the slope of the wick, which can be orientated to reduce reflection and present the largest possible surface area to the incoming solar irradiation. The second parameter is the smaller amount of water present in the porous wick, which heats up more rapidly to produce greater evaporation rates. However, unlike basin stills that store heat in the basin water, wick-based stills have lower efficiencies under lower solar irradiation levels. In spite of this disadvantage, of wick-based stills have attracted considerable research interest over the years [58]. In particular, a wide variety of wick materials like wool, nylon, jute cloth, coir-mate, charcoal cloth, sponges and cotton cloth have also been extensively studied [59-62]. In addition, a wide range of wick-based solar thermal stills that include: 1) wick-based basins [59, 63, 64]; 2) finned basin and wick [65]; 3) floating wick types [60, 66-68]; 4) multi-wick configurations [61, 69-72], and 5) wickbased types with reflectors $[73,74]$ have all been studied and evaluated.

Another method for improving heat and mass transfers within a solar thermal still is to incorporate a series of stepped and cascading weirs. The stepped-weirs, with shallow water depths, are designed to increase the surface area of water exposed to solar irradiation and promote greater evaporation rates [37]. Several studies have investigated the heat storage capacity, energy efficiencies and water production rates of several types of inclined stepped-weir-based solar thermal stills. For instance, Tabrizi et al. have studied the performance of a single basin solar still containing 15 steps. Each step had a weir height of $5 \mathrm{~mm}$ and a length of $59 \mathrm{~cm}$. Their study found the thermal efficiency of the still was directly related to the residence time of the saline water in the weirs and the amount of solar irradiation received [75]. In a similar study, Halimeh et al. were able to establish that still efficiency was directly proportional to the amount of solar irradiation received and the saline water inlet temperature [76]. While experimental and theoretical studies of a stepped-weir solar thermal still by Sadineni et al. found water production levels were around $20 \%$ higher when compared to a basin solar still operating under similar conditions [77].

Studies have also evaluated the performance of solar thermal stills with unconventional shapes and configurations. Traditionally, the conventional solar thermal still has a rectangular floor plan and trapezoidal side elevation. But recent research has focused on alternative design configurations like triangular, pyramid, spherical and tubular [78]. Triangular and pyramidal configurations have been studied using both mathematical modelling techniques and experimental methods [79]. Both experimental and parametric analysis of triangular and pyramidal solar thermal stills have revealed their efficiencies are influenced by decreasing water depths, changing the orientation of the still, varying glass cover slope and by variations in climatic factors like decreasing solar irradiation, increasing cloud cover and increasing wind speed [80-82]. Above all, climatic factors have a direct effect on the performance of a solar thermal still [83]. For example, a study by Ravishankar et al. that investigated the performance of a triangular shaped pyramid still found the optimal productivity was achieved when water levels were minimal and wind speeds were typically around $4.5 \mathrm{~m} / \mathrm{s}$ [84]. In a similar study, Ahsan et al. found the efficiency of a triangular shaped still was inversely proportional to its water depth and almost proportional to the amount of solar radiation it received [80]. Furthermore, the performance of both triangular and pyramidal shaped solar stills 
are improved by incorporating devices such as reflective mirrors and fans. For example, a study by Arunkumar et al. has found the incorporation of reflective mirrors into a pyramidal shaped solar still can increase water production from 1.52 to $2.9 \mathrm{~L} / \mathrm{m}^{2}$ per day [85]. Moreover, a study by Kianifar et al. has found the inclusion of a circulating fan into a pyramidal shaped solar still increased the evaporation rate and increased still efficiency by around $20 \%$ [86].

Hemispherical and spherical shaped solar thermal stills have the advantage of being able to collect greater amounts of solar irradiation. Studies of hemispherical solar stills have shown the water depth has an inverse effect on water productivity and thermal performances. For instance, Ismail et al. has found when the saline water depth is increased by $50 \%$, the thermal efficiency of the still deceases by $8 \%$ [87]. However, some studies have shown the performance of hemispherical shaped solar stills was similar to stepped-weir solar stills (fitted with condenser) and pyramidal shaped solar stills with double or triple basins $[88,89]$. On the other hand, a study by Panchal et al. has found the performance of a hemispherical shaped solar still was superior to a single-inclined glass covered single-basin still [90]. And a further study by Arunkumar et al. has shown flowing water over a hemispherical shaped solar stills cover can increase its efficiency from $34 \%$ up to $42 \%$ [44]. Similarly, Dhiman et al. have studied a spherical shaped solar thermal still (fitted with a glass cover), that contained a centrally located blackened metallic tray containing saline water. During operation, the saline water brine depth was maintained by a continuous flow into and out of the tray. Condensation occurs on the inner surface of the spherical glass cover. And because of its shape, the condensed water droplets flow downwards to a collecting trough located at the bottom of the still. The study found the spherical shaped still had an efficiency $30 \%$ greater than a conventional singlebasin still [91].

Unlike hemispherical and spherical shaped solar thermal stills, which are primarily designed to maximize the capture of solar radiation, tubular shaped stills have a simplified design configuration which makes them easier to fabricate. They consist of an outer transparent tubular cover surrounding a centrally located blackened metallic tray that runs along the full length of the tube. The depth of the saline water contained in the tray is maintained by a continuous flow of saline water entering and leaving the tray. Condensation occurs on the inner surface of the cover. The condensed water droplets then flow downwards to a collecting trough located at the bottom of the tube. Experimental studies have shown the material used to make the transparent cover can influence the performance of the still. For instance, covers made of polythene sheeting are lighter, more durable and more easily fabricated into tubes when compared to vinyl chloride sheeting. And studies have also revealed solar stills with vinyl chloride covers have lower productivity levels compared to stills with polythene covers. The lower productivity levels are due to the immobility of condensed water droplets on the vinyl chloride surfaces $[92,93]$. Whereas, light-weight polythene covers have been shown to improve the average cumulative condensation mass and in turn improved water productivity [94].

Water diffusion is another method that has been investigated and evaluated for use in a solar thermal still. In a simple water diffusion still, two vertical and parallel partitions separated by a small air-filled gap are located close to a basin. Solar irradiation passes through the glass cover and encounters the first partition. The first partition absorbs solar irradiation (hot partition) and increases in temperature. When saline feed water flows over the heated partition, water vapor is generated and diffuses across the air-filled gap. On arrival, the water vapor condenses on the front surface of the second partition (cold partition). Importantly, the thickness of the air gap is kept small 
in order to suppress convective heat transfer between the two partitions. Once formed, water droplets trickle downwards under the influence of gravity and are collected in a drainage trough located at the lower end of the solar still $[95,96]$. Generally, several hot and cold partition pairs are combined in series to improve productivity. This type of configuration is known as a vertical multiple effect diffusion still and schematic of this configuration is presented in Figure 3 (b).

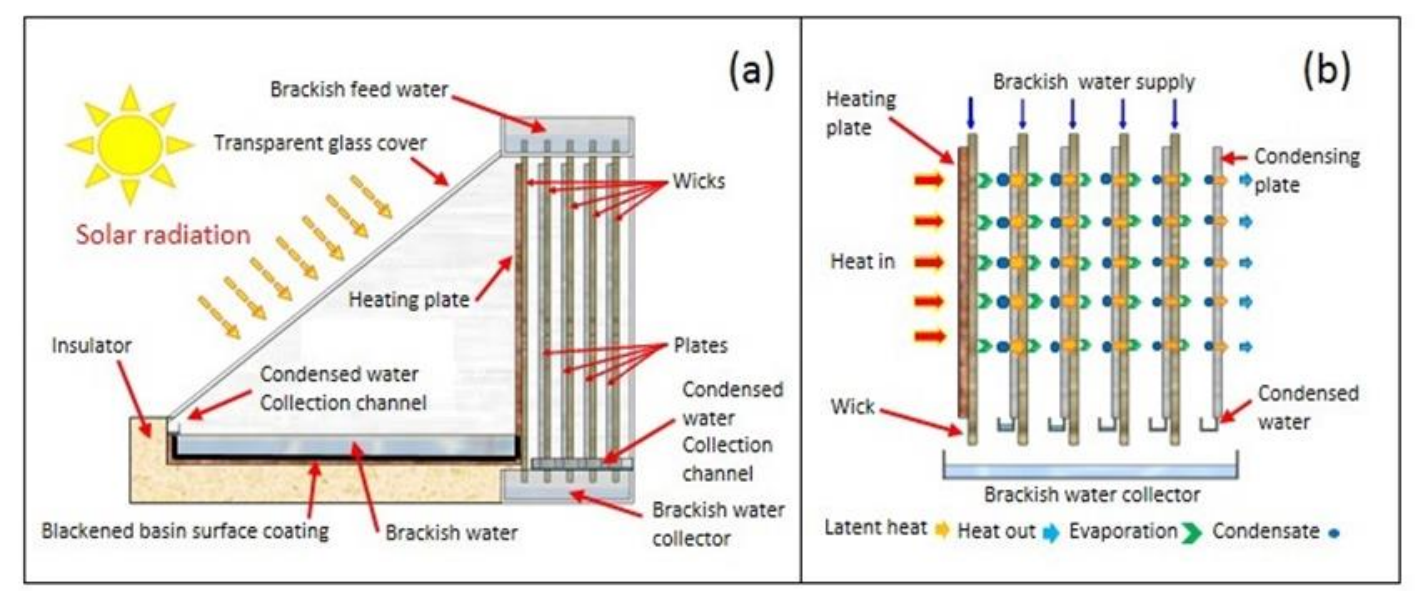

Figure 3 A schematic representation of (a) Multiple-effect diffusion coupled with single slope basin solar still (b) Distillation process inside the multiple-effect diffusion unit.

Further improvements in performance can be achieved by incorporating wick systems onto the hot partition. Importantly, latent heat resulting from condensation on one partition is recovered and assists in further evaporation from the wick system on the next partition [97]. Thus, the repeating evaporation and condensation process significantly improves the overall performance of the solar thermal still. In addition, several studies have also investigated combining multiple effect diffusion stills with conventional basin type solar stills (Figure 3 (a)), flat plate collectors and hotpipe solar collectors to further improve performance and water productivity [98-100].

From another perspective, combining solar thermal stills with greenhouses creates a unique approach for developing horticulture in arid locations where only saline water exists [101]. In the greenhouse-based concept two different configurations have been investigated. The first configuration consists of the solar thermal still being oriented and installed on the sun facing part of the greenhouse roof [102]. While in the second configuration, the basin of the solar still is horizontally oriented and located below the glass roof of the greenhouse [103]. In both cases solar irradiation heats up saline water that was first pumped up to the basin. The heated saline water evaporates, then condenses as pure water on the overhead glass covers and is finally collected. But unlike a conventional solar thermal still arrangements where the bulk of the solar radiation is used to heat water, in the greenhouse-based configuration, part of the energy is transmitted via conduction, convection and radiation to horticultural crops and soil below the still. Importantly, most of the available solar irradiation is absorbed by the solar still, which results in lower air temperatures in the greenhouse. This leads to better climate control and reduces the amount of ventilation needed to cool the greenhouse. This results in lower water consumption by crops and promotes greater crop yields [103].

2.2.1.2 Active Systems. The most important features of solar stills are their technical simplicity, low maintenance costs and their non-reliance on fuel fossils to operate. Unfortunately, the overall 
thermal performance and water productivity of solar thermal stills is relatively low [104]. However, in recent years several proactive methods have been investigated in order to improve the thermal performance and water productivity of conventional passive solar thermal stills [105]. These active solar thermal still systems require additional components or equipment, which are integrated with the still to improve overall system performance. The integration of fans, condensers and pumps, along with components like flat plate solar collectors, pre-heated water from solar ponds and heat exchanges have been evaluated in recent years [78]. Typically, the integration of ancillary equipment also requires mechanical, electric and thermal energy inputs to operate them. Thus, unlike the abovementioned passive solar thermal stills, active solar thermal stills require external sources of energy like electricity to drive pumps, fans and instrumentation.

The incorporation of an external flat plate solar collector has been found to significantly increase input water temperatures to a solar thermal still, which in turn leads to greater evaporation rates and higher water production rates [106]. Figure 2 (b) and (d) presents typical solar thermal still with external flat plate solar collectors. Interestingly, several studies have shown the optimum shape for a passive solar still is rectangular. But in the case of active solar thermal stills this is not the case. A study by Arslen's group examined the performance of several different active solar still designs incorporating a solar collector and found the circular solar still was far more efficient than a standard rectangular box configuration [107]. The improved performance was credited to the lower heat losses occurring from the smaller surface area resulting from the circular still design. Another method of improving solar still performance is to boost solar irradiation capture with integrated reflecting mirrors [39]. Furthermore, studies have also shown that sun-tracking systems can significantly improve thermal performance by as much as 50\% [108]. Typically, the incorporation of flat plate solar collectors and reflecting mirrors significantly increase the evaporation rate and water productivity of solar thermal still. Furthermore, Voropoulos et al. have shown the performance of a solar thermal still can be further increased by the addition of an integrated solar collector field. Their study found basin water heating continued throughout the day, and well into the night period. This extended heating period lead to higher temperature differences and resulted in the still producing twice as much fresh water when compared to the passive mode (no solar collectors) [109].

The performance of single basin solar thermal stills can be improved with the incorporation of evacuated tube solar collectors [110]. These configurations can raise basin water temperatures quickly and achieve thermal efficiencies of around 33.8\% [111]. Alternatively, other studies have looked at collecting solar irradiation over a large area and then focusing the irradiation onto a small receiver area. This type of configuration significantly boosts the amount of energy that is available for solar thermal desalination. For instance, Chaouchi et al. have designed a parabolic concentrator with a small boiler located at its focus. The steam generated in the boiler is condensed via a heat exchanger to produce pure water that collected in a trough located at the bottom of the unit [112]. Alternatively, Zeinab and Ashraf have studied the performance of a conventional rectangular solar basin still fitted with a parabolic trough collector and heat exchanger. Solar irradiation was focused by the parabolic reflector onto a centrally located oil carrying pipe. The circulating oil travels from the collector to a heat exchanger located in the stills basin. The oil is cooled by the basin water before cycling back to the collector. The heat from the circulating oil increases basin water temperatures. Their study revealed the stills performance increased by $18 \%$ when compared to the passive mode (no collector or oil circulation) [113]. Alternatively, other studies have not only incorporated external solar collectors, but have also included heat absorbent materials or phase 
change materials (PCM) into the solar still design. For example, a study by Arunkumar et al. incorporating a concentrator and a PCM increased still water production performance by $26 \%$ [114]. While a study by Farshad et al. reported a $12 \%$ increase in water production during the night period when a sand-based heat reservoir was built-in to the basin [115].

Increasing basin water temperatures is a major factor in improving solar thermal still performance. Therefore, pre-heating basin water from an alternative source is advantageous, especially if waste heat can be recovered from nearby industries and power generation facilities. Thus, installing a heat exchanger in the basin promotes greater heat transfer rates and leads to greater evaporation rates [116]. To this end, several researchers have investigated a number of methods for integrating a solar pond into a solar thermal still [117]. Both single basin and steppedweir solar stills have shown significant improvements in heat transfers and evaporation rates when combined with solar ponds [118]. For example, a study by El-Sebaii et al. found the performance of a single basin solar still increased when it was coupled to a shallow solar pond. With daily water production increasing by $52.36 \%$ and the overall efficiency increasing by $43.80 \%$ when compared to the still without the solar pond connected [119]. Alternative studies have also shown the incorporation air heaters, external condensers, PCMs and water spraying arrangements can increase still performance by as much as $70 \%$. However, higher performances were only achieved when air heaters were used in conjunction with thermal energy storage systems and water spraying arrangements [120-122]. Furthermore, adding a separate condenser to a solar thermal still can Increase its performance by around 30\% [123]. The performance improvement resulted from greater condensation rates generated by the condenser $[124,125]$.

\subsubsection{Multiple-effect Solar Stills}

Multiple-effect solar thermal stills have higher thermal efficiencies and superior water production rates than single-effect solar stills. The increased water productivity arises from continually reusing the latent heat of condensation to evaporate more water. For example, water vapor generated from one basin can be condensed on the underside of a second basin, thus releasing heat (latent heat of condensation) to help drive evaporation from the second basin, as seen in Figure 2 (c). Thus, multiple-effect solar thermal stills are designed to overcome the low thermal efficiencies and low water productivities that are seen with single-effect solar stills [42].

2.2.2.1 Passive Systems. Multiple-effect passive solar thermal stills have been extensively studied for a number of years. During this period several types of still configurations like basin, diffusion, stepped-weir and wick have been thoroughly studied. And each of these configurations have been optimized to exploit the latent heat of condensation in one stage of the still to further evaporate water in another stage. For instance, the integration of multiple-basins into a still can significantly improve its thermal performance and productivity. Adding extra basins means larger amounts of water, which equates to an increase in water heat capacity within the still. And the larger water heat capacity translates to a greater utilization of the latent heat of condensation, which in turn increases water productivity [126]. A number of studies have compared the performance of a double-basin still with a single-basin still and found the double-basin still consistently outperformed the single-basin. In the double-basin configuration, the lower basin was found to be more productive than the upper basin, while the overall heat loss from the lower basin was reduced by the upper basin $[126,127]$. While a study by Sebaii et al. found the water productivity of a triple- 
basin still was inversely proportional to the amount of water mass in each basin, and the water productivity of a triple-basin still was greater than either a single-basin or a double-basin still [128]. Furthermore, a modelling study by Sangeeta et al. has found the maximum number of basins for optimum performance in an inverted absorber-type solar still was seven [129]. While a numerical study by Madhlopa et al. has found the inclusion of a separator to a multiple-basin still could improve water productivity by $62 \%$ [130].

Alternative studies have also examined the influence of the glass cover slope (inclination angle) and the effect of flowing water over the glass cover. For instance, the optimal glass cover slope was reported to be $23^{\circ}$ for a multiple-effect solar thermal still located at Muscat, Oman (latitude angle $23.61^{\circ}$ ) [127]. While the influence of water flowing over an inclined glass cover, above a doublebasin solar still, was found to lower the glass surface temperature [131]. Crucially, the reduced temperature promoted both condensation and air circulation within the still. With the increased air circulation increasing the evaporation rate of both basins [132]. While other reports investigating multiple-basin stills have also studied the influence of basin water levels, the inclusion of energy storage materials and materials used to fabricate the solar still $[43,133]$. For instance, a study by Rajaseenivasan et al. examined the influence of water depths, wick materials and energy storage materials. Their study found lower basin water levels and the use of energy storage materials improved productivity by $169.2 \%$ when compared to stills with higher water levels and no energy storage materials [134].

Another passive system is the multiple-effect diffusion-based solar thermal still, as shown in Figure 3 (a). The main part of this still is a series of plates arranged parallel to each other with a small air gap between each plate, as seen in Figure 3 (b). Diffusion-based stills are classified by their respective plate orientation, which can include horizontal, inclined and vertical. The interest in multiple-effect diffusion-based stills stems from their higher water production rates when compared to convention single slope basin type stills. The higher water production rates are the result of recycling the latent heat of condensation several times across the plate assembly, as seen in Figure 3 (b) $[95,135,136]$. A recent study by Kaushal et al. involved modifying a conventional single basin solar still to include multiple floating wicks in the basin, a vertical diffusion-based module and a heat exchanger for recovering waste heat [137]. Their study found the water production rate in the modified still was $21 \%$ higher than the unmodified still. The increased performance was found to be the result of pre-heating feed water, higher convective heat transfer and evaporation by wicks, and the multiple-effect diffusion stage. While a parametric study by Tanaka et al. has found the performance of multiple-effect diffusion still coupled with a basin type solar still was four times more productive than a conventional basin-type still and $40 \%$ more productive than a traditional multiple-effect solar still. Their study also revealed productivity was dependent on increasing ambient temperatures, minimal basin water volumes, the number of plates and smaller air gaps between the individual plates in the diffusion still [138].

A number of studies have also shown multiple-effect based multi-wick solar thermal stills are not only simple to construction and easier to maintenance, but they also have high water productivities $[59,64]$. Studies have also shown that double layered wicks are more efficient than single layered wicks and higher operating temperatures improve the overall still performance [66, 70, 72]. In addition, a study by Singh et al. found the thermal performance of the first effect was much higher than the second effect of a double-effect multiple-wick solar still. And the thermal efficiency of the still decreased with increasing saline flow rates [139]. While studies of multiple-effect stepped weir 
solar thermals stills have revealed regulating the airflow through vents in the first effect promotes greater evaporation and condensation rates in the second effect [140]. Similarly, a study by Abdullah et al. that investigated the performance of a stepped-weir solar still equipped with an air heater and a glass cooling module. Their study found when both heating and glass cooling were applied, still water productivity increased by $112 \%$ compared to the non-applied mode [121]. While a study by Dastban et al. found the presence of paraffin wax (PCM) in a stepped-weir still improved its performance by around $31 \%$ when compared to the still without wax [141].

2.2.2.2 Active Systems. Multiple-effect solar stills have been integrated with a wide variety of evacuated tube collectors, solar collectors, solar ponds and heat exchanges. A number of studies have shown the integration of evacuated tube collectors increases the performance of multipleeffect solar thermal stills $[142,143]$. For instance, a study by Mahkamov et al. found the integration of evacuated tube collectors to a multi-effect still could double its productivity compared to the still without the tube collectors [144]. Similarly, a study by Kabeel et al. found incorporating evacuated tube collectors into the feed-line increased water temperature and improved the performance of a stepped-weir solar still by $57.3 \%$ compared to the still without collector tubes [145]. In addition, like passive basin type solar stills, multiple-basins can be used to effectively generate multiple-effects that involve vapour from one basin being condensed on the underside of another basin. Thus, the resulting condensation releases heat to drive further evaporation in other basins. While a report by Patel et al. studying the effects of coupling single sloped solar stills (single-basin or double-basin) with evacuated glass tubes found the pre-heating effect increased water productivity in both still types. With the double-basin still productivity being around $14.7 \%$ higher than the single-basin still [146]. Similarly, a study by Deshmukh et al., with the inclusion of reflector mirrors, found the productivity of a double-basin configuration was between 50.8 and $62.1 \%$ higher when compared to the single-basin configuration [147].

In an alternative study, Alaudeen et al. integrated an inclined flat plate collector into the feedline of a stepped-weir solar still and found a $16.36 \%$ improvement in performance when compared to the still without the plate collector [148]. While in a study by El-samadony et al., which added an external condenser and internal reflectors to a stepped-weir solar still, found water productivity could be increased by $165 \%$ [149]. Moreover, a studies by Kumar et al. found the inclusion of PCMs into a multiple-effect stepped- weir still could increase its productivity by as much as 35\% [150, 151].

Table 1 presents a selection of solar thermal still types and their respective performance enhancements when compared to the still without the added feature. Crucially, the performance of active multiple-effect solar thermal stills, like other types of solar thermal stills, is heavily dependent on environmental factors, design parameters and operational factors. For instance, several studies have demonstrated the importance of water depth in governing both thermal performance and water productivity $[54,152,153]$. The importance of these factors cannot be ignored, therefore, these factors must be taken into account when designing and fabricating highly productive and efficient solar thermal stills. To this end, the following section discusses the important factors that influence the performance and water productivity of a solar thermal still. 
Table 1 A selection of solar thermal still types and performance enhancements.

\begin{tabular}{|c|c|c|c|c|}
\hline Mode & Still type & Feature & Enhancement & Ref. \\
\hline Passive & Basin & Cover cooling & 34 to $42 \%$ & {$[44]$} \\
\hline \multirow{9}{*}{ Single effect } & \multirow{2}{*}{ Basin } & Mirrors \& Ext. Condenser & $77 \%$ & [49] \\
\hline & & Mirrors & $70 \%$ & {$[50]$} \\
\hline & \multirow{2}{*}{ Basin } & Basin Fins & $40 \%$ & \multirow{2}{*}[51]{} \\
\hline & & Basin corrugations & $21 \%$ & \\
\hline & Basin & $\begin{array}{l}\text { Heat storage materials } \\
\text { black granite gravel }\end{array}$ & 17 to $20 \%$ & {$[52]$} \\
\hline & Wick & Inclusion of wicks & 16 to $50 \%$ & [57] \\
\hline & Stepped-weir & Series of weirs increase water surface area & $20 \%$ & [77] \\
\hline & Pyramidal & Inclusion of fan & $20 \%$ & {$[86]$} \\
\hline & Hemispherical & flowing water over cover & $34 \%$ to $42 \%$ & [44] \\
\hline Active & basin & Reflectors \& sun tracking & $>50 \%$ & {$[108]$} \\
\hline \multirow[t]{3}{*}{ Single effect } & Basin & Evacuated tubes collectors & $33.8 \%$ & {$[110]$} \\
\hline & basin & $\begin{array}{l}\text { Parabolic trough collector and heat } \\
\text { exchanger }\end{array}$ & $18 \%$ & [113] \\
\hline & Basin & Solar pond connected & $43.8 \%$ & [119] \\
\hline Passive & Basin & Multi-basin and condenser & $62 \%$ & [130] \\
\hline \multirow[t]{4}{*}{ Multi-effect } & Basin & $\begin{array}{l}\text { Lower water levels and energy storage } \\
\text { materials }\end{array}$ & $169.2 \%$ & {$[134]$} \\
\hline & Basin & $\begin{array}{l}\text { Floating wicks, heat exchanger, diffusion } \\
\text { module }\end{array}$ & $21 \%$ & [137] \\
\hline & Wick & Enhanced wick orientation and material & $42 \%$ & {$[72]$} \\
\hline & Stepped-weir & Addition of paraffin wax (PCM) & $31 \%$ & {$[141]$} \\
\hline Active & Stepped-weir & Evacuated tube collectors in feed-line & $57.3 \%$ & {$[145]$} \\
\hline Multi-effect & Stepped-weir & Flat plate collector in feed-line & $16.36 \%$ & {$[148]$} \\
\hline
\end{tabular}

\section{Factors Influencing Solar Thermal Still Performance}

In spite of being an ideal and viable solution for generating high quality water from saline water, solar thermal stills have a major disadvantage. This disadvantage is their low production rates (ranging between 2 and $5 \mathrm{~L} / \mathrm{m}^{2} /$ day), which makes them less economically competitive when compared to other desalination processes with much higher water production rates [154, 155]. The factors influencing the performance of a solar thermal still can be grouped into three categories. The categories include: 1) environmental factors; 2) design and fabrication factors, and 3) operational factors. The categories and their respected factors are listed in Figure 4 and individually discussed in in the following sections. 


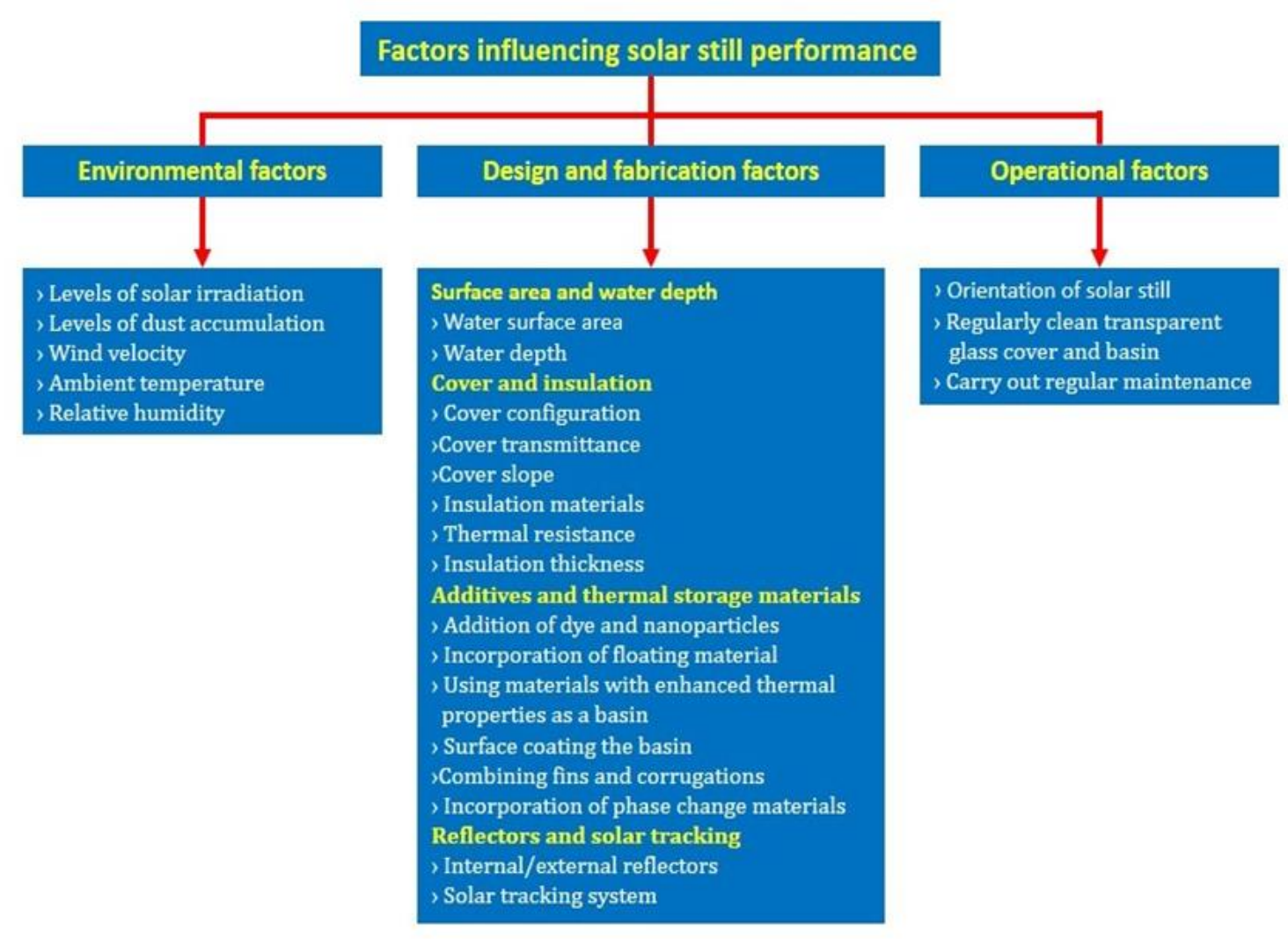

Figure 4 Factors influencing the performance of a solar thermal still.

\subsection{Environmental Factors}

Environmental factors can directly influence the thermal efficiency and water productivity of a solar thermal still. Solar irradiation is the most important factor, since the operational principle of a solar thermal still is based on heating, evaporating saline water and condensing water vapor to produce high quality water. Therefore, the performance of a solar thermal still is directly influenced by the levels of solar radiation it receives [156]. Several studies have shown high levels of solar irradiation increase still performance by producing larger temperature differences between the basin water and the glass covering [157]. Thus, higher levels of solar irradiation, particularly at optimal periods during the day, increase basin water temperatures and in turn increase evaporation rates $[32,158]$. Studies have also shown the importance of the transparent cover in transmitting solar radiation and its ability to condense water vapor [159]. Moreover, factors like cloud cover and surface contamination of the cover can significantly reduce the amount of solar radiation entering the solar still [160]. In particular, studies have shown increasing levels of dust accumulation on the cover can decrease the transmission of solar radiation by as much as $70 \%[161,162]$. Thus, covers need to be regularly cleaned to promote maximum transmission.

Wind speed is an important factor because it cools the covering and promotes still productivity. Studies have shown large temperature differences between the covering and basin water results in improved air circulation within the still. Greater air circulation has been shown to improve evaporation rates, increase condensation rates, and consequently promote larger water productivities $[163,164]$. Moreover, while studies have reported increasing wind velocities promote still performance, other studies have shown obstacles preventing wind circulation around the still 
have an adverse effect on the still $[157,165]$. Other environmental factors, which cannot be controlled include ambient air temperature and the relative humidity of the surrounding atmospheric air. Studies have shown increasing ambient air temperatures tend to increase solar still performance $[154,166,167]$. While other studies have shown increasing amounts of atmospheric humidity increase still productivity $[164,168]$.

\subsection{Design and Fabrication Factors Contributing to Solar Thermal Still Productivity}

To date, considerable research has gone into investigating the design factors governing the performance of a solar thermal still. This is because it is only during the design stage that these factors can be controlled, optimized and implemented during the fabrication of the still [42]. The major design factors that have been investigated are listed in Figure 4 and Table 2. Numerous studies have examined these factors and their influence on solar thermal still performance. With the specific objectives of increasing evaporation and condensation rates, improving thermal efficiencies and increasing water productivity rates $[32,169]$. The following sections of this review summarize the current state of research into optimizing these factors, and methods that have been adopted to increase water productivity rates.

\subsubsection{Water Surface Area Exposed to Evaporation and Water Depth}

Several studies have shown solar thermal still evaporation rates and water production rates increase with increasing exposure of water surface area to solar radiation $[27,167]$. Over the years, numerous methods were specifically developed to increase the surface area of water within the still. Methods like including wicks, jute cloth, sponges, charcoal blocks, rubbers and floating surfaces have improved evaporation rates by as much as $80 \%[60,65,101]$. Interestingly, a study by AbuHijleh et al. found the inclusion of sponge cubes in a single-basin solar still dramatically increased the evaporation rate and boosted water production by $273 \%$ when compared to a sponge free still [55]. While a study by Kabeel et al. investigating the influence of both depth and width of trays in a stepped solar still, found the most favorable tray size was $5 \mathrm{~mm}$ deep and $120 \mathrm{~mm}$ wide. The optimized tray size increased still water production by $57.3 \%$ when compared to the unmodified still [170]. The lower water depth in the trays is the reason why water productivity from stepped stills is higher than single-basin stills $[121,146]$. Similar studies have also found water depth an important design factor, since lower water depths result in higher water temperatures [43, 171]. And higher water temperatures generate larger evaporation rates [80]. Thus, evaporation rates and water productivity are both inversely proportional to water depth during the day time period. However, during the night time period the opposite is true, since low water levels equate to less heat being stored in the water. Therefore, solar stills with deeper water levels will have more heat stored in the water mass. So during the night time period, stored heat is released, and the still continues to produce water without any solar energy contribution [172].

\subsubsection{Cover and Insulation}

There are two functions of cover. Firstly, it should provide a cool surface for water vapor condensation to place. Secondly it must allow solar irradiation to travel into the still. During still operation, condensation forms on the underside of the cover, so the slope of the cover must be 
sufficient to facilitate droplet flow towards a collecting trough fitted along the entire length of the cover, as seen in Figure 1. Importantly, the cover must also maximize the transmission of solar energy, with minimal reflectance. And at the same time it must have sufficient insulation properties to prevent excessive thermal radiation from the basin water escaping to the external environment $[108,173]$. In spite of the various cover designs (domes, bi-layered semi-sphere and arch configurations), studies have shown the inclined flat glass cover is the most effective way of producing water $[45,46]$. Studies have also shown the water productivity of a single-sloped solar still is higher than a double-sloped solar still in colder climates. But the opposite is true in warm climates [39, 46]. In addition, the covers angle of slope also directly influences its productivity [93]. With studies showing larger cover slopes producing more condensate during winter than during summer $[32,47]$. Furthermore, studies have also shown flowing cooling water at uniform velocities over the cover can improve condensate production levels by as much as $100 \%[44,48]$.

The thermal efficiency of a solar thermal still can be improved by preventing heat losses to the environment [174]. Thus, an important design parameter is the selection of suitable insulating materials that can prevent heat escaping from the still [175]. Several studies have investigated the performance of various insulating materials like saw dust, glass wool, Styrofoam, polyurethane, fiber glass and nitrile rubber $[59,65,110,113,176,177]$. In particular, a study by Hashim et al. has reported insulating materials like air gaps, plywood, hay, and glass wool improved still water productivity by $74 \%, 82 \%, 126 \%$, and $130 \%$ respectively when compared to non-insulated stills [178]. All of these studies have highlighted the importance of using thick insulating materials with high thermal resistances to promote higher thermal efficiencies and water productivities.

\subsubsection{Additives and Thermal Storage Materials}

In an effort to improve the thermal performance and overcome lower water production rates a number of studies have focused on increasing the thermal capacity of the solar still system and recovering the latent heat of condensation $[40,179]$. Two methods for achieving these goals include the addition of basin water additives and thermal storage materials into the still system [180-184]. Several studies have reported the addition of dyes into basin water can significantly improve still performance. Since the introduction of a dye not only darkens the water, but it also increases the amount of solar energy being absorbed by the basin water. Thus, increasing solar energy absorption will result in more rapid water heating $[154,157]$. Also, the addition of floating materials into basin water like charcoal pieces has been found to improve still performance [101]. For instance, Srivastava and Agrawal found the addition of floating blackened jute cloth absorbers in a singlebasin solar still significantly improved its performance. Their study found the resulting capillarity effect present in the absorbers increased the surface area of basin water exposed to solar radiation. The increased expose to solar radiation resulted in higher basin water temperatures and greater evaporation rates. With water productivity levels increasing by $68 \%$ for clear days and $35 \%$ for cloudy days [185]. Alternative studies have found fabricating the basin out of materials with enhanced thermal properties can also improve still performance. For instance, materials like cement, galvanized iron or aluminum sheeting, fiber reinforced plastics, black rubber, and gravels have been used [87, 186]. Importantly, these materials not only encourage solar energy absorption, but their high heat storage capacity also promotes longer evaporation rates. In addition, coating the basin liner with photo-catalyst materials like $\mathrm{CuO}, \mathrm{PbO}_{2}$ and $\mathrm{MnO}_{2}$ or painting the black can also enhance 
solar energy absorption $[172,187]$. And in recent years, a wide range of new nanometer scale materials have attracted considerable interest due to their unique thermo-physical properties. Their use as additives, or as part of the solar still structure is currently being studied by several researchers [188]. This new avenue of research will be discussed in more detail in section 4.

More traditional methods of improving performance also include installing finned or corrugated basins to solar stills $[51,79]$. For instance, the installation of fins into a basin can increase its performance by $40 \%$, while corrugated basins were found to have performance increases of around $21 \%$ [51]. A further study found the inclusion of floating sponges into a basin could improve still performance by $60.4 \%$. While basins fitted with fins only produced still improvements of around 76\%. However, when both fins and sponges were installed into the basin, their combined enhancement resulted in a still performance of around 96\% [189]. A similar study also found basins fitted with fins and containing both sponges and fine pebbles were capable of performance improvements of around 98\% [190]. While the incorporation of just a thermal storage material like black granite gravel in a basin can increase water productivity of a still by as much as $20 \%$ [52]. Thus, highlighting how important additives to the basin can be for improving still performance [191].

In recent years there has been number studies investigating the use of phase change materials (PCM) as a method of improving the performance of several solar thermal still types [192, 193]. PCM materials with melting temperatures between 50 and $80{ }^{\circ} \mathrm{C}$ are ideal for storing and releasing thermal energy within a solar still $[181,194,195]$. During the day time period, large amounts of heat is stored in the PCM. The during the night time period the stored heat is slowly released to maintain water evaporation. Thus, effectively extending the operational period of the solar still beyond day light hours. A variety of PCMs, their properties and costs, and their suitability for solar thermal still applications have been evaluated in recent years [196]. For instance, a recent study by Al-harahsheh et al. using a single basin solar still found sodium thiosulfate pentahydrate was a good PCM. And that water productivity was significantly improved, with over $40 \%$ of the production being generated after sunset [197]. Importantly, there is a greater temperature difference between basin water and still cover during night time hours and this results in increased condensation rates [198]. Because the inclusion of a PCM in a solar still can promote greater evaporation and condensation rates, many researchers have also incorporated other types of enhancements to further boost water productivity [182, 199, 200]. For instance, Shalaby et al. has reported using paraffin wax (with a melting point of $56^{\circ} \mathrm{C}$ ) as the PCM in a v-corrugated single-basin solar still. Their study revealed daily water productivity of the still increased by $12 \%$ when compared to the still without the paraffin wax [31]. While a study by El-Sebaii et al. using a single basin solar still incorporating stearic acid as the PCM, found daily water production increased by $80.17 \%$ when compared to the still without PCM [201].

\subsubsection{Reflectors and Solar Tracking}

Mirror reflectors are used to direct solar energy towards the solar still. Because more solar radiation is directed towards the solar thermal still there is an increase in water productivity. For instance, a study has found by replacing a single-basin with a stepped-basin, and installing reflecting mirrors on all interior surfaces, the thermal performance of the still was increased by $30 \%$ [108]. And a study by Omara et al. found the performance of a stepped-weir still with reflecting mirrors fitted on all of the vertical step could improve water productivity by $57 \%$ when compared to the 
non-mirrored still [202]. Studies have also shown the installation of external reflectors can also improve solar still performance [203]. Similar studies have also investigated the feasibility of using concave mirrors and parabolic trough collectors to direct solar energy to the solar still [204, 205]. While Monowe et al. have fitted an external reflector and an external condenser to a single-basin solar still and found the combined arrangement improved water productivity by around $77 \%$ [49]. In addition, Tanaka has used a combination of internal and external reflectors to increase the water productivity to between 70 and $100 \%$ for a single-basin still [50]. Similar studies for basin type solar stills fitted with external reflectors and wicks have also shown significant improvements in their water productivity rates [74, 206]. While modelling studies by Tanaka and Nakatake have shown that fitting both internal and external reflectors to a single-basin solar still improves its year-round average daily water productivity by $48 \%$ [207]. And in recent years several researchers have also investigated the use of Fresnel lens to improve the performance of single-sloped and double-sloped basin type solar stills $[208,209]$. With a recent study by Johnson et al. reporting a $638 \%$ improvement in water productivity for a single-basin solar still fitted with a Fresnel lens [210]. Other researchers have investigated performance enhancements to solar thermal stills by using suntracking systems [211]. For instance a study by Eltawil and Zhengming investigating the efficiencies of a combined solar still and inclined solar water distillation unit found when sun-tracking was operational daily efficiencies improved. Efficiencies improved between 66.81 and $69.01 \%$ for the solar still and between 57.08 to $62.38 \%$ for the inclined system [176].

\subsection{Operational Factors}

The optimal performance of a solar thermal still is dependent on operational factors like orientation, maintenance and repair of the structure, and cleaning of both the basin (salt deposition) and the cover (dust accumulation). The water productivity increases with greater amounts of solar radiation entering the solar thermal still. The solar still needs to face towards the sun (adjusted for latitude position), so that it receives the maximum amount of solar energy throughout the year [186]. Crucially, the solar still is heavily dependent on its fixed position and orientation relative to incident solar energy. So it is important that the optimal position and orientation in achieved [96].

During the design of a solar thermal still, the cost of materials must be considered in terms of longevity. Because if improper materials are selected then corrosion issues can become a major maintenance problem. The selection of corrosion free materials will improve system reliability and prolong the operational life span of the still. Corrosion problems can be avoided by using high quality materials like copper, stainless steel and fiber glass pipes and fittings during the fabrication still [212, 213]. The selection of good quality materials is important, since carrying out regular maintenance in remote and rural locations may not be possible. For instance, corrosion can occur when the basin is being filled with saline water or discharged during cleaning operations. There are two methods of supplying saline water to the basin. The first is the static method and involves filling the basin once a day. The second method is the dynamic method and involves intermittently filling the basin during the day $[75,187]$. Corrosion resulting from this daily process can be avoided if fiber glass reinforced plastic piping is used [213].

During solar still operation undesirable salts and minerals are deposited on the basin liner. And in many cases algae also forms on the surface of basin water [214]. Therefore, an important operational procedure is to regularly clean the basin. This can be done by daily flushing of the basin 
or by using dilute non-toxic acid solutions to remove mineral build-ups. However, if the basin is intermittently or continuously filled, dissolved solids and impurities maybe flushed and in this case the frequency of cleaning will be reduced. Another operational factor that needs to be considered is the negative impact resulting from the discharge of basin mineral deposits, pre-treatment chemicals and cleaning materials into the environment [215]. Since, these waste materials can have detrimental effects on both fauna and flora, as well contaminate soils and ground waters [216, 217].

Also, after long periods of operation the solar still cover needs cleaning. On the inside of the still, the cover becomes coated with a thin layer of particulates. This layer reduces the amount of solar energy entering the still and also reduces the flow of condensate to the collection troughs within the solar still [47]. On the outside, dust accumulates over the cover and reduces the amount of solar energy entering the still. Thus, the water productivity of solar still decreases with increasing levels of dust accumulation. Therefore, cover cleaning needs to be carried out on a regular basis to maintain the optimal performance of the solar thermal still all year round.

Section 3 has summarized the factors that influence the thermal efficiency and water productivity of a solar thermal still. The three categories of factors included environmental, design and fabrication, and operational parameters. Environmental factors that directly influenced water productivity of a solar still were found to be the amount of solar energy captured, ambient air temperature, relatively humidity and wind speed. Several design and fabrication factors were also found to play an important role in influencing the performance of a solar still. Each of these factors and their respective effects were summarized, with factors and key effects being listed in Table 2 . In addition, operational factors influencing the operation of the solar thermal still were discussed, with important operational parameters being listed in Table 2.

Table 2 Summary of environmental, design \& fabrication and operational factors influencing a solar thermal stills performance.

\begin{tabular}{|c|c|c|c|}
\hline Category & Factor & Key Effect & Ref. \\
\hline \multirow[t]{5}{*}{ Environmental } & Solar irradiation & $\begin{array}{l}\text { Increasing solar energy increases evaporation } \\
\text { rates }\end{array}$ & [158] \\
\hline & Dust accumulation & $\begin{array}{l}\text { Increasing dust levels reduces solar } \\
\text { transmission through cover }\end{array}$ & [162] \\
\hline & Wind velocity & $\begin{array}{l}\text { Moderate wind velocities promotes still } \\
\text { productivity, }\end{array}$ & [165] \\
\hline & Ambient air temperature & $\begin{array}{l}\text { increasing ambient air temperatures increase } \\
\text { still productivity }\end{array}$ & [167] \\
\hline & Relative humidity & Increasing humidity increases still productivity & [168] \\
\hline \multirow[t]{4}{*}{$\begin{array}{l}\text { Design } \\
\text { Fabrication }\end{array}$} & Water surface area & $\begin{array}{l}\text { increasing water surface area promotes greater } \\
\text { evaporation }\end{array}$ & [167] \\
\hline & Water depth & Increasing water depth lowers evaporation rate & {$[171]$} \\
\hline & Cover configuration & $\begin{array}{l}\text { Flat glass cover is the most effective way of } \\
\text { producing water }\end{array}$ & {$[45]$} \\
\hline & Cover transmittance & $\begin{array}{l}\text { Maximize transmittance and minimal } \\
\text { reflectance. }\end{array}$ & [108] \\
\hline
\end{tabular}


Cover slope

Insulating materials

Thermal resistance

Insulation thickness

Addition of dyes

Addition of nanoparticles

Incorporation of floats

Enhanced materials

Basin surface coatings

Fins \& corrugations

Phase Change Materials

Int./Ext. reflectors

Parabolic \& Fresnel lens

Solar tracking systems
Inclination equal to a latitude angle will receive consistent solar radiation over year

Wide range to select from

Use materials with high thermal resistance

Insulation thickness improves water productivity

Dyes in basin water increases thermal efficiency

Improve thermal capacity of still

Coatings improve solar radiation adsorption

Improves basin thermal efficiency

Extends evaporation rates into the night

Directs more solar energy into the still

Concentrates solar energy input to the still

Directs still to sun, hence more solar energy input

Optimal position and orientation for maximum solar energy input all year round

Regularly clean basin and Reduces salt deposits in basin and removes dust cover from cover increases transmittance

Carry out regular Regular maintenance maintains the still for maintenance optimal performance all year round

\section{New Approaches and Advanced Materials}

Solar thermal desalination is a straightforward and appealing due to its eco-friendly approach that only relies on solar energy to drive the process [26, 28, 105]. However, as mentioned earlier, solar thermal desalination technologies have lower thermal efficiencies and lower water production rates compared to other forms of desalination. The low performance results from heat being transferred into the water volume and not being directly used in the evaporation process. However, in recent years solar thermal desalination has attracted considerable interest due to the development of new nanometer scale materials, enhanced phase change materials and innovative interfacial heating systems. In this section, we summarize these recently developed materials and approaches for improving evaporation rates in solar thermal desalination systems. In the first part, we discuss the use of plasmonic nanoparticles (volumetric absorbers) to improve evaporation through the efficient photothermal conversion of solar energy [218, 219]. In the second part, we discuss the performance enhancement produced when nanometer scale materials are incorporated 
into phase change materials (PCMs) [220]. And in the third part, we discuss interfacial solar evaporation systems that are designed to localize solar irradiation at the air-water interface and increase evaporation rates [221]. Importantly, each of these new approaches can significantly improve evaporation rates under one-sun illumination. Furthermore, each of these new approaches is an attractive desalination strategy, especial if combined with conventional solar thermal still configurations.

\subsection{Volumetric Absorbers for Water Vapor Generation}

As mentioned earlier, heat transfer into the water volume is not fully utilized in the evaporation process. A recently developed method for overcoming this problem is to use volumetric absorbers. These absorbers are photothermal materials capable of absorbing incident light over a wide range of the solar spectrum. The absorbed light is converted into thermal heat by photoexcitation. This photothermal effect can be widely seen in various nanometer scale materials that exhibit strong light absorption properties and high light-to-heat conversion rates. In this method nanometer scale particles are suspended in the basin water (nanofluid) to improve its heat transfer properties and evaporation rate, as seen in Figure 5 [34, 222]. Nanoparticles are small clusters of tightly packed atoms that are typically less than $100 \mathrm{~nm}$ in one dimension. At this scale, many nanomaterials are highly polarizable and strongly interact with incident electromagnetic (light) radiation. And when the frequency of incident light and the natural frequency of electrons present on the surface of the nanoparticle match, it produces an excitation resonance or plasmon. The collective excitation of the electrons generates localized heating around the nanoparticle [223]. Thus, in the context of a solar thermal system, incident solar energy is absorbed by the nanofluid and excites the nanoparticles. For each nanoparticle, the resulting plasmon heats a thin layer of water (particle-liquid interface) to boiling. The resulting vapor formation nucleates a bubble [224]. As heating continues, the low thermal conductivity of the forming vapor prevents heating of the surrounding bulk water, and as a consequence the bubble grows in size. Bubble growth continues until a critical size is reached. At this point, the resulting buoyancy force causes the bubble to migrate to the water-air interface [225]. On reaching the water-air interface, only the vapor escapes and the nanoparticle once again undergoes the vapor generation cycle [226]. Critically, during the vapor generation cycle, evaporation occurs at temperatures well below the boiling point of water [227]. Furthermore, studies have also shown evaporation rates can be further improved by localized nanoparticle light scattering in regions close to the water-air interface $[228,229]$. However, if nanoparticle concentrations become large, the resulting back scattering of solar radiation at the water-air interface becomes problematic. Since the resulting backscatter can significantly reduce the amount of solar radiation entering the nanofluid. Therefore, nanofluids composed of low concentrations of nanoparticles will permit larger amounts of solar energy to propagate, which in-turn will promote greater numbers of light-matter interactions to take place. Importantly, low concentrations also mean these interactions will take place well below the water-air interface. Thus, highlighting the importance of nanofluid depth as a critical factor in the design of a solar thermal system.

Studies have investigated a wide variety of nanoparticle types for suspension in aqueous-based solutions [226, 230]. Several researchers have reported conversion efficiencies as large as $80 \%$, with the remaining incident solar radiation being lost to the water bulk [226, 227, 230]. Typical material types evaluated for nanoparticle-based vapor generation include noble metals, metal oxides, core- 
shell and carbon-based. For instance, when gold $(\mathrm{Au})$ nanoparticles were suspended in aqueous solutions and illuminated, they were found to efficiently convert solar irradiation to heat [231, 232]. Studies have also shown higher solar thermal conversion efficiencies can be achieved under higher solar concentrations. For example, a recent study by Amjad et al. found it possible to achieve a solar thermal conversion efficiency of $95 \%$ using a water-based Au nanofluid (composed of $0.04 \mathrm{wt}$. \% of Au nanoparticles). During the study, the nanofluid was used to generate steam when exposed to a solar irradiation level that was equivalent to 280 suns [233]. Similarly, Jin et al. found a water-based Au nanofluid (composed of $12.75 \mathrm{ppm}$ Au nanoparticles) achieved a solar thermal conversion efficiency of $80.3 \%$ under a solar irradiation level that was equivalent to 220 suns [232]. Alternatively, other researchers have investigated the use of various core-shell type nanoparticles to generate water vapor under normal solar irradiation levels [229]. For instance, when exposed to one sun solar irradiation, the pressure above an aqueous-based nanofluid containing $\mathrm{SiO}_{2} / \mathrm{Au}$ nanoshells was found to increase within $5 \mathrm{~s}$. Thus, confirming the generation of water vapor above the air-water interface [226]. Likewise, when exposed to solar irradiation, water vapor was generated above an aqueous-based nanofluid containing hollow nano-shells composed of an Ag/Au alloy [234].

Metal oxide nanoparticles have also attracted the interest of several researchers. For instance, a study by Kabeel et al. focused on increasing solar thermal still water productivity by incorporating metal oxide nanoparticles into its basin water. Their study investigated two types of metal oxide nanoparticles, the first being cuprous oxide and the second being aluminum oxide. Their results revealed the addition of cuprous oxide nanoparticles increased water productivity by $133.6 \%$ and when aluminum oxide nanoparticles were tested water productivity increased by $125 \%$ [235]. Similarly, a study by Wang et al. has found $\mathrm{Ti}_{2} \mathrm{O}_{3}$ nanoparticles, which possess strong light absorption properties, have the potential to be used in solar desalination and purification applications [236]. Recent studies have also shown a wide variety of carbon-based materials like graphite, graphene, graphene oxide and carbon nanotubes have excellent broadband solar absorbance properties due to their sp2-hybridized carbon atomic structure and $\pi$-band optical transitions [237]. For instance, when an aqueous-based nanofluid composed of carbon (N115) nanoparticles was exposed to solar radiation, it immediately generated water vapor above its air-water interface [226]. Similar studies of other aqueous-based nanofluids containing carbon materials like carbon black, graphitized carbon, and graphene have all been found to generated significant amounts of water vapor [218, 238-241]. However, no matter what type of nanoparticle is used to produce a nanofluid, nanoparticle concentration is an important factor. Since high concentrations will prevent the propagation of solar radiation within the nanofluid. In addition, high concentrations also lead to nanoparticle agglomeration and greater nanofluid instability [242].

\subsection{Enhancing the Thermal Properties of Phase Change Materials with Nanoparticles}

A major disadvantage of relying on solar irradiation for the operation of a solar thermal system is its intermittency. For instance, under cloudy conditions solar irradiation levels are low, and during the night-time period it is not available. Hence, incorporating a thermal energy storage unit within a solar thermal system can assist in maintaining water productivity during periods when solar irradiation is not available [243]. One strategy for storing energy is via the latent heat method. In this method, heat generated from solar irradiation changes the enthalpy of a storage material. During the heating period a phase change process takes place. Phase change materials (PCMs) can 
store large quantities of heat, which can be released during periods when solar irradiation is not available [244]. Traditional PCMs like paraffin, organic esters and n-eicosane have poor thermal conductivities ( 0.2 to $0.7 \mathrm{Wm}^{-1} \mathrm{~K}^{-1}$ ), which limits their heat transfer efficiency [245]. However, several recent studies have reported the use of dispersed thermally conductive nanomaterial structures being combined with traditional PCMs to improve their thermal performance [220, 246, 247]. Typical nanomaterials investigated include metals (e.g. $\mathrm{Au}, \mathrm{Ag}, \mathrm{Cu}$ ), metal oxides (e.g. $\mathrm{Al}_{2} \mathrm{O}_{3}, \mathrm{CuO}$, $\left.\mathrm{MgO}, \mathrm{TiO}_{2}, \mathrm{ZnO}\right)$ and carbons (e.g. carbon, graphene, graphite) $[248,249]$. For instance, a study by Parameshwaran et al. has found the addition of Ag nanoparticles (10-18 nm and $5.0 \mathrm{wt}$. \%) into an organic ester produced a $67 \%$ improvement in thermal conductivity [250]. While a similar study by Deng et al. has have found the addition of Ag nanowires (dia. of 50-100 nm, and length of 5-20 $\mu \mathrm{m}$, and 19.3 wt. \%) into polyethylene glycol produces an incredible $1130 \%$ improvement in thermal conductivity [251]. In addition, other studies have reported similar thermal conductivity improvements for a variety of PCMs [252]. For instance, a study by Cui et al. found the addition of copper nanoparticles (10-30 nm and $0.5 \mathrm{wt}$. \%) into sodium acetate trihydrate increased the PCMs thermal conductivity by $25 \%$ [253]. And a study by Rufuss et al. found the addition of copper oxide nanoparticles (40 nm, $0.3 \mathrm{wt}$. \%) into paraffin wax produced a $25 \%$ increase in its thermal conductivity [254]. Similarly, a study by Yang et al. found the addition of $\mathrm{Si}_{3} \mathrm{~N}_{4}$ nanoparticles (at 10 wt. \%) into paraffin increased its thermal conductivity by $35 \%$ and increased its thermal diffusivity by $47 \%$. Thus, confirming the performance enhancement of the PCM [255]. Other studies have also found the addition of metal oxide nanoparticles like $\mathrm{TiO}_{2}$ and $\mathrm{Al}_{2} \mathrm{O}_{3}$ can also improve the thermal conductivity of a PCM. For instance, Sharma et al. have found the addition of $\mathrm{TiO}_{2}$ nanoparticles (21 $\mathrm{nm}, 5.0 \mathrm{wt}$. \%) into palmitic acid improved its thermal conductivity by $80 \%$ [256]. While a study by Nourani et al. found the inclusion of $\mathrm{Al}_{2} \mathrm{O}_{3}$ nanoparticles (10-20 nm, 10.0 wt. \%) into paraffin wax improved its thermal conductivity by $43 \%$ [257]. And in recent years several carbon-based materials like graphite, graphene, and carbon nanotubes have also been used to enhance the thermal conductivity of PCMs like paraffin wax, n-eicosane/silica and palmitic acid [258-263]. For instance, as study by Karaipekli et al. found the addition of carbon nanotubes (dia. $6-9 \mathrm{~nm}$, length $5 \mu \mathrm{m}, 1.0$ wt. \%) into n-eicosane increased its thermal conductivity by $113 \%$ [264]. While a study by Li found the inclusion of graphite nano-platelets (dia. $15 \mu \mathrm{m}$, length $35 \mathrm{~nm}, 10.0 \mathrm{wt} . \%$ ) in paraffin wax improved its thermal conductivity by $167 \%$ [265]. Moreover, a study by Fang et al. found the addition of graphene nano-platelets (4-20 nm thick, $10.0 \mathrm{wt}$. \%) into n-eicosane impressively improved its thermal conductivity by $400 \%$ [266].

Each of the abovementioned studies have demonstrated the advantage of dispersing thermally conductive nanomaterials into pure PCMs as an effective method for improving their thermal performance. Thus, improvements in the thermal conductivity of PCMs translates into an increase in their effectiveness as a thermal energy storage unit. Studies have also found the inclusion of small concentrations of nanomaterials can also improve solidification, melting rates, phase change process and heat storage rate. Importantly, the studies have also shown the performance of the nanomaterial in the PCM is dependent on its thermal conductivity and aspect ratio [245, 267]. Importantly, studies have shown carbon-based nanomaterials (carbon nanotubes and graphene) are the best thermal conductivity improvers for the enhancement for PCMs [268-270]. However, studies have also reported discrepancies between simulation studies and experimental measurements. For instance, studies have shown significant discrepancies between thermal 
conductivity and viscosity [271-273]. Therefore, further research into developing new empirical models for determining the thermo-physical properties of nanomaterial enhanced PCMs is needed.

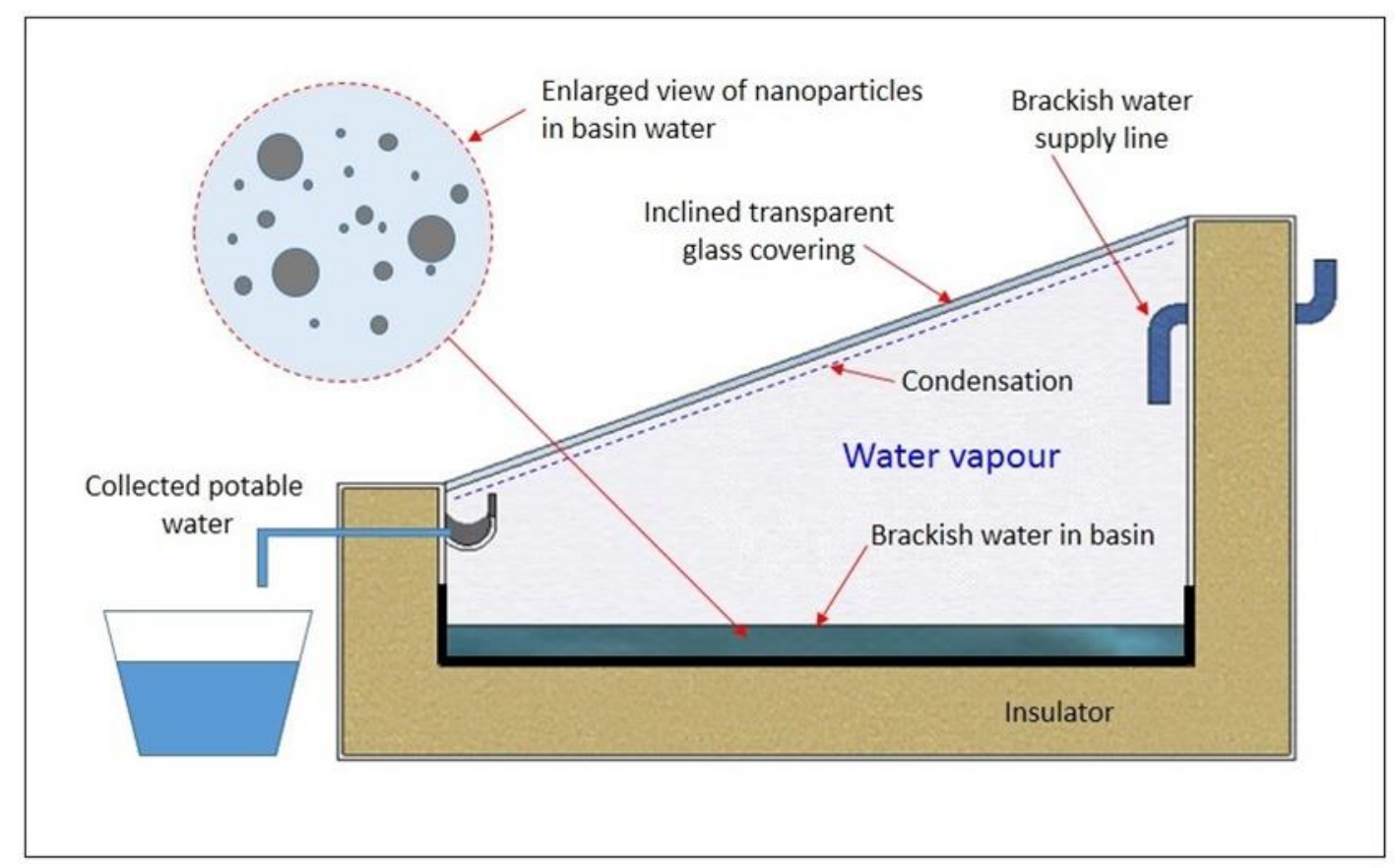

Figure $\mathbf{5}$ The addition of nanomaterials to enhance photothermal properties of basin water.

\subsection{Floating Solar Absorbers for Water Vapor Generation}

In recent years research has focused on developing interfacial (floating) solar evaporation systems for desalinating saline water $[25,274]$. Unlike conventional solar thermal stills, a solar evaporation system has a photothermal absorber located on the water-air interface. Thus, ensuring water located at the interface is heated rather than the surrounding bulk water. This type of design configuration has been found to significantly increase photothermal efficiency [275]. A typical design consists of several components that include an absorber and support substrate, incident solar energy, saline water reservoir, water vapor and collector, as seen in Figure 6 . The incident solar irradiation is collected, absorbed and converted into heat by the absorber. The underlying support substrate, with vertically aligned water channels, permits the upward passage of saline water via capillary forces [276]. On reaching the upper surface of the absorber, the saline water is rapidly heated and evaporated. This process is continuous if the absorber is exposed to sunlight and supplied with saline feed water. The evaporation efficiency of this process is less than $100 \%$, due to the absorber losing heat to the environment as seen in Figure 6. However, in recent years the evaporation efficiency has steadily increased to around $85 \%$ due to the development of new photothermal materials and innovative system designs [24, 277, 278]. Thus, making interfacial solar evaporation a very attractive eco-friendly method for generating high quality drinking water without contributing to global warming and pollution [279-281]. 


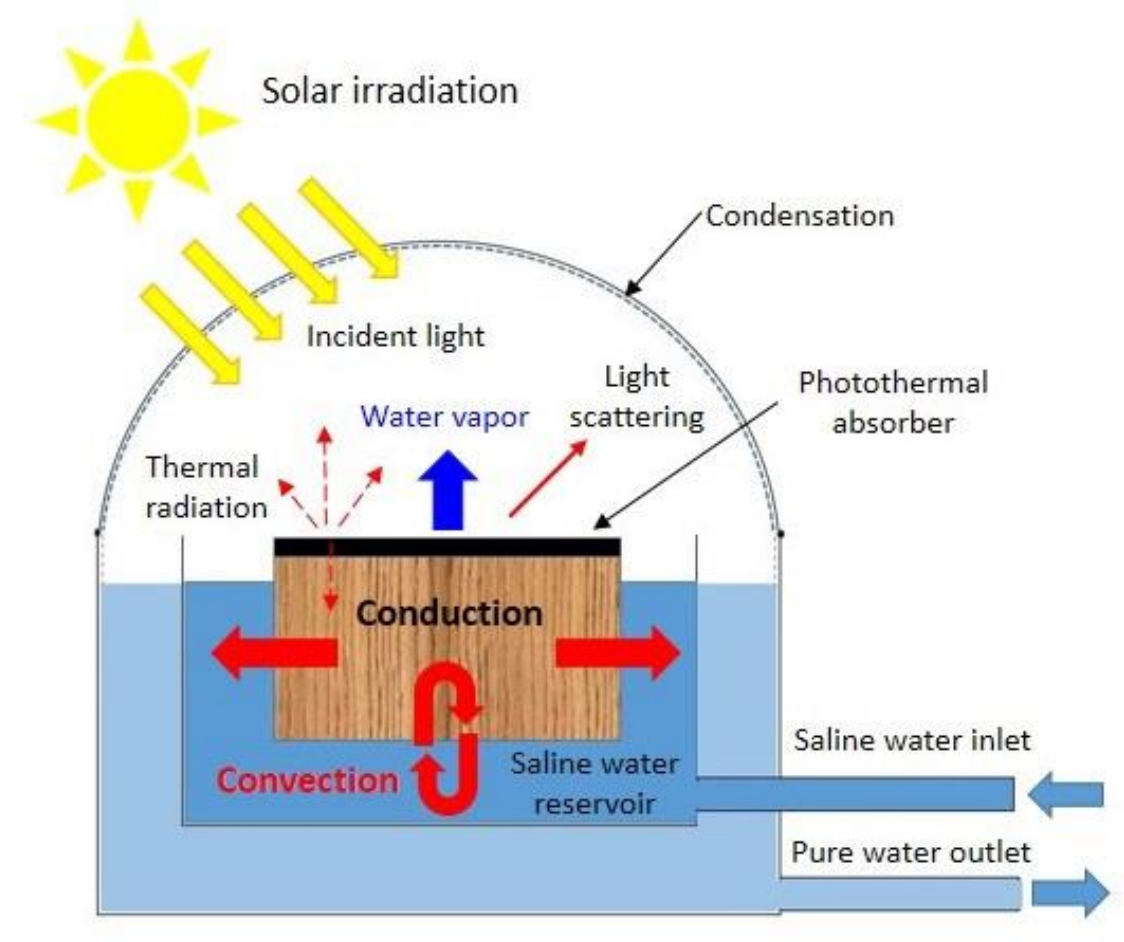

Figure 6 Schematic representation of an interfacial solar evaporation system.

The most important component of an interfacial solar evaporation system is the double-layered absorber and underlying support substrate. Crucially, the evaporation efficiency of the absorber/substrate is heavily dependent on its properties. Absorbers must be photothermal materials with high light absorption properties across the solar spectrum and superior light-to-heat conversion rates. While substrates must be good thermal insulators with excellent water transporting properties. Therefore to be effective vapor generator, absorbers must have the following important properties: 1) absorb light across a wide range of wavelengths ( 380 to $2500 \mathrm{~nm}$ ) and have a high-efficiency light-to-heat conversion; 2) capable of confining the generated heat to the evaporative surface for maximum evaporation and minimizing heat losses to the environment; and 3 ) the porous substrate should have good interface wettability and a well-designed structure for achieving continuous and efficient water transport form the underlying saline water reservoir to the upper evaporative surface [282, 284]. However, achieving optimal outcomes for all these properties is challenging. For instance, the substrate can have a well-developed water-pathway for promoting a strong capillary effect. But when the water-pathways are filled, thermal conductivity of the substrate increases and more heat is conducted to the underlying saline water reservoir. To avoid this situation, some studies have examined methods of separating the thermal insulation structure from the water-pathway structure to reduce heat losses and promote higher evaporation rates $[285,286]$.

Several studies have also investigated incorporating various nanomaterials and/or fabrication strategies to improve light absorption and/or light-to-heat conversion rates. Ideally, a light absorber should absorb as much solar energy as possible across the entire solar spectrum. To achieve this goal, several studies have investigated two methods of increasing light absorption in the visible and near-infrared regions of the spectrum. The first method involves incorporating metallic nanoparticles into an absorber to increase light adsorption. For instance, both $\mathrm{Au}$ and $\mathrm{Al}$ 
nanoparticles have been incorporated into free-floating plasmonic films, and both $\mathrm{Au}$ and $\mathrm{Ti}$ nanoparticles have been included in porous absorbers [287-290]. While the second method uses lithographic techniques to generate nanometer scale structures over the absorber surface. These surface features can be roughening, patterning or straight pores. Each of these surface features are designed to increase light adsorption via multi-scattering effects [291]. However, top-down lithographic techniques for fabricating these features are technologically challenging and are currently not cost effective.

Alternatively, carbon materials have been studied for potential use as absorbers in solar evaporation systems due to their high light absorption across a wide range of wavelengths. Typically, most natural surfaces like tree leaves and wood have solar absorptivity's of less than 55\% [292]. While carbon materials like carbon black, graphite, graphene oxide and carbon nanotubes, have solar absorptivity's greater than $90 \%$ [293, 294]. The high absorptivity's of carbon materials is due to optical transitions that result from excited electrons moving from the $\pi$ orbital to $\pi$ * orbital [295]. These optically excited electrons quickly convert their energy into heat via lattice vibrations within the material. Carbon materials, like carbon black [296], graphite [32, 297], graphene [298, 299], graphene oxide [300,301] and carbon nanotubes [302,303] have all proven to be photothermal materials suitable for use as solar absorbers. Moreover, natural organic materials and structures, such as trees, wood stems, mushrooms, grass, cotton, and other plant materials, can be carbonized to become practical solar absorber materials [304-307].

Another important feature of a solar evaporation system is the underlying substrate material. Ideally, the substrate needs to have a low thermal conductivity to maximize its thermal insulation and a porous structure to maximize the flow of water to the evaporation zone. Based on these requirements, several studies have examined a wide variety of materials for potential use as substrates. Commercially available thermal insulators, like polystyrene and polyurethane forms, have been extensively used in interfacial solar evaporators [308, 309]. Several other materials, like air-laid paper, silicon dioxide aerogels, alumina membranes, graphene oxide aerogels and carbon nanotubes, have also been investigated and found to be efficient substrates [282, 289, 294, 310, 311]. In particular, studies have investigated using natural materials like cellulose for producing foam substrates [312]. Plant-based materials are hydrophilic and multi-channeled so that water can freely travel from the roots to the leaves. And because of this ideal structure there has been extensive research into using natural materials or replicating these materials to make artificial substrates [313, 314].

Natural wood is predominantly composed of cellulose, it is hydrophilic, it has well-aligned vertical water channels and has a low thermal conductivity. In fact, it possesses all the properties needed for an efficient substrate. Because of these features, several studies have focused on using wood as a substrate material [315-317]. Typically, a wood absorber/substrate is made by first cutting suitably sized blocks with the water channels orientated vertically. Then the upper surface is carbonized using a hot plate in air. The resulting rough black carbonized thin layer has an extremely high light absorption of around 95\% [295]. However, for other natural materials, like mushrooms, a tubefurnace and a protective gas atmosphere is used for the carbonization process [305]. When the bilayer wood-based absorber/substrate is placed in a saline water reservoir and illuminated by incident light, it quickly heats up and starts evaporating water, as seen in Figure 6. The underlying water channels in the substrate ensure a continuous supply of saline water from the reservoir to the upper evaporative surface via capillary action [318]. The non-carbonized surfaces of the wood 
substrate act as a thermal insulator to reduce the loss of generated heat to the saline water reservoir and surrounding environment, as seen in Figure 6. An intriguing result of surface carbonization is its increased resistance to decay when compared to the non-carbonized surfaces [319]. In addition, carbonized wood also has longer survivability than non-carbonized wood when exposure to aquatic environments [320]. Another intriguing development, apart from hot plate carbonization, is coating the upper surface of the absorber with photothermal materials like graphite, graphene oxide, carbon nanotubes and plasmonic nanoparticle coatings as a method of improving evaporative performance [313, 321-324].

\subsection{Challenges and Future Perspective}

Solar thermal desalination has made remarkable progress in the past decade. Improving design configurations, enhanced design \& fabrication parameters and optimized operational factors have all contributed to improving thermal efficiency and water productivity. However, it has been the remarkable progress made in developing new photothermal/substrate materials that has had the greatest impact. Moreover, using solar evaporation is the most promising eco-friendly and zero carbon footprint technologies for producing high quality water [277, 325]. However, despite the recent advances made in solar evaporation, there are both fundamental research and practical challenges that need to be explored before this technology can be used for large-scale desalination.

Major factors contributing to the overall performance of solar thermal systems is their long-term stability against the water source and the local environment. The water source may come from ground water, industrially contaminated water, river water or seawater. Each of these water sources has particular challenges. For instance, the presence of bacteria and other microbial organisms in the source water can cause biofilm formation within the solar device and reduce its performance over time. Similarly, heat, photothermal degradation due to ultraviolet light and weathering of structures can all reduce overall performance of the facility [25, 314]. Thus, further materials engineering research is needed to investigate water/structure surface chemistries, and then develop appropriate protective coatings. In addition, some water sources maybe contaminated with volatile organic components which might evaporate with the water during processing, and then condense with the condensate to produce low quality water. In this case, new methods of detecting, handling and processing these contaminants is needed to prevent contamination of the output water product. Furthermore, if nanoparticles are used in the solar evaporation system, then suitable nanoparticle surface coatings are needed to overcome their highly reactive nature and maintain their chemical stability [275].

Another important challenge arises from the accumulation salt during the continuous generation of vapor at the heating surface of an interfacial solar evaporation system. During normal operation two problems occur. The first problem comes from the accumulation of salt, which forms a layer over the heating surface. Unfortunately, the resulting salt layer reflects incident solar irradiation and reduces the solar-thermal conversion rate [326]. The second problem is more serious, the accumulating salt blocks the water pathways and dramatically reduces the evaporation rate [313]. At present the only two effective methods for removing salt blockages are physical removal and backwashing. Both methods are undesirable, since they both require taking the solar evaporation system off-line. In both cases, system downtime increases, operational costs increase and lost water 
productivity. Thus, solar absorbers with salt rejection properties are needed to overcome this problem.

Despite the advances made in developing new materials and designs for solar thermal evaporation, there needs to be a better understanding of the underlying mechanisms and processes involved. For instance, many studies have focused on vapor generation under solar radiation [291, 324]. However, vapor generation can only be achieved with efficient light to heat conversion rates, effective water transportation and favorable thermal diffusion processes. Therefore, a fundamental understanding of the dynamic processes involved is needed, so that the most effective strategies can be achieved for optimal performance. For example, thermal diffusion (conduction, convection and radiation) through the absorber/substrate needs to be fully investigated. Especially, developing methods for reducing heat losses from the absorber/substrate assembly. While water transport properties and physical properties of the substrate also need to be quantified. Surface properties like wettability need also to be further investigated so the most water compatible materials can be identified and used. Also, protective treatments to prevent bio-fouling of the pores in the underside of the substrate are also needed. Moreover, substrate physical properties like porosity, pore size, pore structure and tortuosity need to be quantified so that water transport behavior can be fully explained. To complement these additional experimental studies, there is also a need for simulation studies to assist with gaining a better understanding of the underlying mechanisms and behaviors of light/heat transfers, water transport and thermal diffusion through the absorber/substrate structure.

To achieve a successful outcome, more work is needed to determine the effectiveness of this technology. The recent results of interfacial solar evaporation systems are encouraging, but data regarding cost and scalability is needed before practical applications are possible [327]. Generally, low water production levels of traditional solar thermal systems have made the competitiveness of this technology challenging. From a system point of view, low capital cost and ease of maintenance are important factors, which make this technology attractive for producing high quality water for individual households or supplying water to small communities in remote regions. However, studies have not fully addressed problems associated with increasing scalability, manufacturing costs and operational costs. Recent studies of processes like interfacial solar evaporation have demonstrated the potential to significantly improve thermal efficiency and water productivity. But greater focus on developing larger scalability and cost competitiveness strategies for these innovative materials, processes and structures is needed. Therefore, further studies into these strategies are needed to make solar desalination more competitive in the market place.

Another major challenge facing all desalination processes, not just solar desalination, is their environmental impact. But unlike other forms of desalination, solar desalination doesn't generate or release greenhouse gases to the atmosphere. Since all the energy needed to drive the solar desalination process comes from the sun [2]. However, like all other forms of desalination, solar desalination does discharge brine into the environment [328]. In 2019 global brine discharges were estimated to be around 51.7 billion cubic meters annually [329]. Importantly, factors like pH, salinity, temperature, heavy metals, residual chemicals and reactions byproducts from feed water treatments contribute to the overall toxicity of brine discharges [330, 331]. For instance, studies have shown higher salinity levels and increased water temperatures are present around discharge points and produce a detrimental impact on the local marine ecosystem [332, 334]. Thus, making brine discharges a serious environmental problem. On the other hand, a recent study by Elsaid et 
al. found the use of mitigation and control strategies that incorporated specific design criteria and system improvements in conventional desalination processes could significantly reduce the environmental impact of brine discharges [334]. Therefore, further studies into mitigation and control strategies specifically designed for solar desalination processes is also needed to reduce the impact of brine discharges into the local environment.

\section{Conclusion}

The present review has provided an overview of the recent progress made towards developing solar thermal processes for producing high quality water. Solar energy is both abundant and renewable. It can provide the energy needed to drive an eco-friendly process with a zero carbon footprint. Generally, solar thermal stills produce relatively low water productivity levels compared to conventional fossil fuel dependent desalination systems. Due to low water productivity levels, recent research into solar desalination has focused on improving water productivity and thermal performance in order to improve its competitiveness. In the past decade several achievements have been made towards improving the performance of solar thermal systems and in the development new photothermal and substrate materials. The first part of the review summarized the various solar thermal still designs, and the environmental conditions, design \& fabrication parameters and operational factors that influence their performance. Environmental conditions cannot be controlled, but design \& fabrication parameters and operational parameters can be adjusted to optimize system performance. The review found factors like large evaporation and condensation surface areas, lower water levels, higher basin water temperatures, minimizing heat losses and cooling covers increased water productivity and thermal efficiency.

The review also summarized recent research into advance materials for improving the solar evaporation via nanometer scale materials and thermal energy storage via PCMs. Plasmonic nanoparticles used in volumetric systems displayed strong light absorption and high light-to-heat conversion rates which generated significant amounts of heat. While the addition of nanomaterials into PCMs was found to enhance their thermal performance. In addition, recently developed interfacial (floating) solar evaporation systems incorporating new photothermal absorbers and substrate materials. These absorbers display high light absorption properties, while their supporting substrates display unique water transportation behavior and thermal properties. Each of these new and emerging technologies can dramatically increase evaporation rates. However, a number of challenges, like long-term nanoparticle stability, material degradation and salt accumulation, remain and require further study to make these eco-friendly and sustainable solar desalination technologies possible.

\section{Acknowledgments}

Mr. Wisut Chamsa-ard would like to thank the Royal Thai Governments Ministry of Science and Technology for a scholarship to undertake his PhD studies at Murdoch University, Australia.

\section{Author Contributions}

All authors contributed equally to this work.

\section{Funding}


Royal Thai Governments Ministry of Science and Technology Scholarship.

\section{Competing Interests}

The authors have declared that no competing interests exist.

\section{References}

1. Mekonnen MM, Hoekstra AY. Four billion people facing severe water scarcity. Sci Adv. 2016; 2: e1500323.

2. Miller $\mathrm{S}$, Shemer $\mathrm{H}$, Semiat R. Energy and environmental issues in desalination. Desalination. 2015; 366: 2-8.

3. Vörösmarty CJ, Green P, Salisbury J, Lammers RB. Global water resources: Vulnerability from climate change and population growth. Science. 2000; 289: 284-288.

4. United Nations. Adoption of the Paris Agreement. Proposal by the President. Paris Climate Change Conference - November 2015; 2015 November 30th- December 11th; Paris, France. Bonn: United Nations Climate Change.

5. Elimelech M, Phillip WA. The future of seawater desalination: Energy, technology, and the environment. Science. 2011; 333: 712-717.

6. Gerland P, Raftery AE, Ševčíková H, Li N, Gu D, Spoorenberg T, et al. World population stabilization unlikely this century. Science. 2014; 346: 234-237.

7. Watkins K. Human Development Report 2006-Beyond scarcity: Power, poverty and the global water crisis. New York (NY): United Nations Development Programme; 2006.

8. Ng KC, Thu K, Kim Y, Chakraborty A, Amy GL. Adsorption desalination: An emerging low-cost thermal desalination method. Desalination. 2013; 308: 161-179.

9. Wallace JS, Gregory PJ. Water resources and their use in food production systems. Aquat Sci. 2002; 64: 363-375.

10. Ghaffour N, Missimer TM, Amy GL. Technical review and evaluation of the economics of water desalination: Current and future challenges for better water supply sustainability. Desalination. 2013; 309: 197-207.

11. Kalogirou SA. Seawater desalination using renewable energy sources. Prog Energy Combust Sci. 2005; 31: 242-281.

12. Helal AM, Al-Malek SA. Design of a solar-assisted mechanical vapor compression (MVC) desalination unit for remote areas in the UAE. Desalination. 2006; 197: 273-300.

13. Ali MT, Fath HE, Armstrong PR. A comprehensive techno-economical review of indirect solar desalination. Renew Sust Energ Rev. 2011; 15: 4187-4199.

14. Shahzad MW, Burhan M, Ang L, Ng KC. Energy-water-environment nexus underpinning future desalination sustainability. Desalination. 2017; 413: 52-64.

15. Roberts DA, Johnston EL, Knott NA. Impacts of desalination plant discharges on the marine environment: A critical review of published studies. Water Res. 2010; 44: 5117-5128.

16. Subramani A, Badruzzaman M, Oppenheimer J, Jacangelo JG. Energy minimization strategies and renewable energy utilization for desalination: A review. Water Res. 2011; 45: 1907-1920.

17. Eltawil MA, Zhao Z, Yuan L. A review of renewable energy technologies integrated with desalination systems. Renew Sust Energ Rev. 2009; 13: 2245-2262. 
18. Tian Y, Zhao C. A review of solar collectors and thermal energy storage in solar thermal applications. Appl Energy. 2013; 104: 538-553.

19. Panwar NL, Kaushik SC, Kothari S. Role of renewable energy sources in environmental protection: A review. Renew Sust Energ Rev. 2011; 15: 1513-1524.

20. Thirugnanasambandam M, Iniyan S, Goic R. A review of solar thermal technologies. Renew Sust Energ Rev. 2010; 14: 312-322.

21. Sorrell S, Speirs J, Bentley R, Miller R, Thompson E. Shaping the global oil peak: A review of the evidence on field sizes, reserve growth, decline rates and depletion rates. Energy. 2012; 37: 709-724.

22. Lewis NS. Toward cost-effective solar energy use. Science. 2007; 315: 798-801.

23. Li C, Goswami D, Stefanakos E. Solar assisted sea water desalination: A review. Renew Sust Energ Rev. 2013; 19: 136-163.

24. El-Dessouky HT, Ettouney HM. Fundamentals of salt water desalination. Amsterdam: Elsevier; 2002.

25. Panangipalli VK, Kumar A, Prakash O, Kaviti AK. Solar stills system design: A review. Renew Sust Energ Rev. 2015; 51: 153-181.

26. Compain P. Solar energy for water desalination. Procedia Eng. 2012; 46: 220-227.

27. Xiao G, Wang X, Ni M, Wang F, Zhu W, Luo Z, et al. A review on solar stills for brine desalination. Appl Energy. 2013; 103: 642-652.

28. Qiblawey HM, Banat F. Solar thermal desalination technologies. Desalination. 2008; 220: 633644.

29. Sharon $H$, Reddy SK. A review of solar energy driven desalination technologies. Renew Sust Energ Rev. 2015; 41: 1080-1118.

30. Kumar KV, Bai RK. Performance study on solar still with enhanced condensation. Desalination. 2008; 230: 51-61.

31. Badran OO. Experimental study of the enhancement parameters on a single slope solar still productivity. Desalination. 2007; 209: 136-143.

32. Ghasemi H, Ni G, Marconnet AM, Loomis J, Yerci S, Miljkovic N, et al. Solar steam generation by heat localization. Nat Commun. 2014; 5: 4449.

33. Zhang L, Tang B, Wu J, Li R, Wang P. Hydrophobic light-to-heat conversion membranes with selfhealing ability for interfacial solar heating. Adv Mater. 2015; 27: 4889-4894.

34. Al-Karaghouli A, Renne D, Kazmerski LL. Solar and wind opportunities for water desalination in the Arab regions. Renew Sust Energ Rev. 2009; 13: 2397-2407.

35. Mousa H, Arabi MA. Desalination and hot water production using solar still enhanced by external solar collector. Desalination Water Treat. 2013; 51: 1296-1301.

36. Shalaby SM, El-Bialy E, El-Sebaii AA. An experimental investigation of a v-corrugated absorber single-basin solar still using PCM. Desalination. 2016; 398: 247-255.

37. Al-Hinai $\mathrm{H}$, Al-Nassri MS, Jubran BA. Effect of climatic, design and operational parameters on the yield of a simple solar still. Energy Convers Manag. 2002; 43: 1639-1650.

38. Abdallah S, Badran OO. Sun tracking system for productivity enhancement of solar still. Desalination. 2008; 220: 669-676.

39. Serrano E, Rus G, García-Martínez J. Nanotechnology for sustainable energy. Renew Sust Energ Rev. 2009; 13: 2373-2384. 
40. Kunze H. A new approach to solar desalination for small-and medium-size use in remote areas. Desalination. 2001; 139: 35-41.

41. Fath HE. Solar distillation: A promising alternative for water provision with free energy, simple technology and a clean environment. Desalination. 1998; 116: 45-56.

42. Venkataraman RT, Murugavel KK, Elango T, Hansen S. A review of different methods to enhance the productivity of the multi-effect solar still. Renew Sust Energ Rev. 2013; 17: 248-259.

43. Phadatare MK, Verma SK. Influence of water depth on internal heat and mass transfer in a plastic solar still. Desalination. 2007; 217: 267-275.

44. Arunkumar T, Jayaprakash R, Denkenberger D, Ahsan A, Okundamiya MS, Kumar S, et al. An experimental study on a hemispherical solar still. Desalination. 2012; 286: 342-348.

45. Tayeb AM. Performance study of some designs of solar stills. Energy Convers Manag. 1992; 33: 889-898.

46. Akash BA, Mohsen MS, Nayfeh W. Experimental study of the basin type solar still under local climate conditions. Energy Convers Manag. 2000; 41: 883-890.

48. Tiwari GN, Mukherjee K, Ashok KR, Yadav YP. Comparison of various designs of solar stills. Desalination. 1986; 60: 191-202.

47. Tiwari GN, Rao VS. Transient performance of a single basin solar still with water flowing over the glass cover. Desalination. 1984; 49: 231-241.

49. Monowe $\mathrm{P}$, Masale $\mathrm{M}$, Nijegorodov N, Vasilenko V. A portable single-basin solar still with an external reflecting booster and an outside condenser. Desalination. 2011; 280: 332-338.

50. Tanaka H. Experimental study of a basin type solar still with internal and external reflectors in winter. Desalination. 2009; 249: 130-134.

51. Omara ZM, Hamed MH, Kabeel AE. Performance of finned and corrugated absorbers solar stills under Egyptian conditions. Desalination. 2011; 277: 281-287.

52. Sakthivel M, Shanmugasundaram S. Effect of energy storage medium (black granite gravel) on the performance of a solar still. Int J Energy Res. 2008; 32: 68-82.

53. Kumar BS, Kumar S, Jayaprakash R. Performance analysis of a " $\mathrm{V}$ " type solar still using a charcoal absorber and a boosting mirror. Desalination. 2008; 229: 217-230.

54. Murugavel KK, Srithar K. Performance study on basin type double slope solar still with different wick materials and minimum mass of water. Renew Energ. 2011; 36: 612-620.

55. Abu-Hijleh BA, Rababa'h HM. Experimental study of a solar still with sponge cubes in basin. Energy Convers Manag. 2003; 44: 1411-1418.

56. Sodha MS, Kumar A, Tiwari GN, Tyagi RC. Simple multiple wick solar still: Analysis and performance. Sol Energy. 1981; 26: 127-131.

57. Zhang X, Xu W, He T, You S, Gao Y, Wang M, et al. Solar thermal system evaluation in China. Int J Photoenergy. 2015.

58. Velliangiri M, Shanmugasundaram K, Sengottain S, Balasundaram J, Chandrasekaran J. Wick type solar stills: A review. Renew Sust Energ Rev. 2013; 20: 322-335.

59. Mahdi JT, Smith BE, Sharif AO. An experimental wick-type solar still system: Design and construction. Desalination. 2011; 267: 233-238.

60. Balasundaram J, Chandrasekaran J, Kumar S. Performance of floating cum tilted-wick type solar still with the effect of water flowing over the glass cover. Desalination. 2006; 190: 51-62.

61. Murugavel KK, Chockalingam KK, Srithar K. An experimental study on single basin double slope simulation solar still with thin layer of water in the basin. Desalination. 2008; 220: 687-693. 
62. Hansen RS, Narayanan CS, Murugavel KK. Performance analysis on inclined solar still with different new wick materials and wire mesh. Desalination. 2015; 358: 1-8.

63. Minasian AN, Al-Karaghouli AA. An improved solar still: The wick-basin type. Energy Convers Manag. 1995; 36: 213-217.

64. Sengar SH, Mohod AG, Khandetod YP, Modak SP, Gupta DK. Design and development of wick type solar distillation system. J Soil Sci Environ Manage. 2011; 2: 125-133.

65. Vellaipandian V, Gopalakrishnan M, Raghu R, Srithar K. Single basin solar still with fin for enhancing productivity. Energy Convers Manag. 2008; 49: 2602-2608.

66. Janarthanan B, Chandrasekaran J, Kumar S. Evaporative heat loss and heat transfer for openand closed-cycle systems of a floating tilted wick solar still. Desalination. 2005; 180: 291-305.

67. Nafey AS, Abdelkader M, Abdelmotalip A, Mabrouk AA. Enhancement of solar still productivity using floating perforated black plate. Energy Convers Manag. 2002; 43: 937-946.

68. Al-Karaghouli AA, Minasian AN. A floating-wick type solar still. Renew Energ. 1995; 6: 77-79.

69. Dhiman NK, Tiwari GN. Effect of water flowing over the glass cover of a multi-wick solar still. Energy Convers Manag. 1990; 30: 245-250.

70. Shukla SK, Sorayan VP. Thermal modeling of solar stills: An experimental validation. Renew Energ. 2005; 30: 683-699.

71. Ohshiro K, Nosoko T, Nagata T. A compact solar still utilizing hydrophobic poly (tetrafluoroethylene) nets for separating neighboring wicks. Desalination. 1996; 105: 207-217.

72. Kassem TK. Optimization the performance of single basin solar still with corrugated wick surface at high places. Int Res J Eng Technol. 2016; 3: 1094-1024.

73. Tanaka H. Tilted wick solar still with external flat plate reflector: Optimum inclination of still and reflector. Desalination. 2009; 249: 411-415.

74. Tanaka H. Tilted wick solar still with flat plate bottom reflector. Desalination. 2011; 273: 405413.

75. Tabrizi FF, Dashtban M, Moghaddam H, Razzaghi K. Effect of water flow rate on internal heat and mass transfer and daily productivity of a weir-type cascade solar still. Desalination. 2010; 260: 239-247.

76. Zoori HA, Tabrizi FF, Sarhaddi F, Heshmatnezhad F. Comparison between energy and exergy efficiencies in a weir type cascade solar still. Desalination. 2013; 325: 113-121.

77. Sadineni SB, Hurt R, Halford CK, Boehm RF. Theory and experimental investigation of a weirtype inclined solar still. Energy. 2008; 33: 71-80.

78. Rufuss DD, Iniyan S, Suganthi L, Davies PA. Solar stills: A comprehensive review of designs, performance and material advances. Renew Sust Energ Rev. 2016; 63: 464-496.

79. Abujazar MS, Fatihah S, Rakmi AR, Shahrom MZ. The effects of design parameters on productivity performance of a solar still for seawater desalination: A review. Desalination. 2016; 385: 178-193.

80. Ahsan A, Imteaz M, Thomas UA, Azmi M, Rahman A, Nik Daud NN. Parameters affecting the performance of a low cost solar still. Appl Energy. 2014; 114: 924-930.

81. Rubio-Cerda E, Porta-Gándara MA, Fernández-Zayas JL. Thermal performance of the condensing covers in a triangular solar still. Renew Energ. 2002; 27: 301-308.

82. Fath HE, El-Samanoudy M, Fahmy K, Hassabou AH. Thermal-economic analysis and comparison between pyramid-shaped and single-slope solar still configurations. Desalination. 2003; 159: 69-79. 
83. Jamal W, Siddiqui MA. Effect of water depth and still orientation on productivity for passive solar distillation. Int J Eng Res Appl. 2012; 2: 1659-1665.

84. Sathyamurthy R, Kennady HJ, Nagarajan PK, Ahsan A. Factors affecting the performance of triangular pyramid solar still. Desalination. 2014; 344: 383-390.

85. Arunkumar T, Jayaprakash R, Prakash A, Suneesh PU, Karthik M, Kumar S. Study of thermo physical properties and an improvement in production of distillate yield in pyramid solar still with boosting mirror. Indian J Sci Technol. 2010; 3: 879-884.

86. Kianifar A, Heris SZ, Mahian O. Exergy and economic analysis of a pyramid-shaped solar water purification system: Active and passive cases. Energy. 2012; 38: 31-36.

87. Ismail BI. Design and performance of a transportable hemispherical solar still. Renew Energ. 2009; 34: 145-150.

88. Rahim NH. Utilization of a forced condensing technique in a moving film inclined solar desalination still. Desalination. 1995; 101: 255-262.

89. Aboul-Enein S, El-Sebaii AA, El-Bialy E. Investigation of a single-basin solar still with deep basins. Renew Energ. 1998; 14: 299-305.

90. Panchal HN, Shah PK. Charperformance analysis of different energy absorbing plates on solar stills. Iranica J Energ Environ. 2011; 2: 297-301.

91. Dhiman NK. Transient analysis of a spherical solar still. Desalination. 1988; 69: 47-55.

92. Ahsan A, Fukuhara T. Evaporativity and productivity of a new tubular solar still. advances in water resources and hydraulic engineering. Berlin: Springer; 2009. pp. 333-338.

93. Nafey AS, Abdelkader M, Abdelmotalip A, Mabrouk AA. Parameters affecting solar still productivity. Energy Convers Manag. 2000; 41: 1797-1809.

94. Ahsan A, Imteaz MA, Rahman A, Yusuf B, Fukuhara T. Design, fabrication and performance analysis of an improved solar still. Desalination. 2012; 292: 105-112.

95. Bouchekima B, Gros B, Ouahes R, Diboun M. Performance study of the capillary film solar distiller. Desalination. 1998; 116: 185-192.

96. Kabeel AE, El-Agouz SA. Review of researches and developments on solar stills. Desalination. 2011; 276: 1-12.

97. Fukuia $\mathrm{K}$, Nosoko T, Tanaka H, Nagata T. A new maritime lifesaving multiple-effect solar still design. Desalination. 2004; 160: 271-283.

98. Tanaka H, Nosoko T, Nagata T. Experimental study of basin-type, multiple-effect, diffusioncoupled solar still. Desalination. 2002; 150: 131-144.

99. Tanaka $\mathrm{H}$, Nakatake $\mathrm{Y}$. Outdoor experiments of a vertical diffusion solar still coupled with a flat plate reflector. Desalination. 2007; 214: 70-82.

100.Tanak H, Nakatake Y, Watanabe K. Parametric study on a vertical multiple-effect diffusiontypesolar still coupled with a heat-pipe solar collector. Desalination. 2005; 171: 243-255.

101.El-Haggar SM, Awn AA. Optimum conditions for a solar still and its use for a greenhouse using the nutrient film technique. Desalination. 1993; 94: 55-68.

102. Chaibi MT, Jilar T. System design, operation and performance of roof-integrated desalination in greenhouses. Sol Energy. 2004; 76: 545-561.

103.Srivastava NS, Din M, Tiwari GN. Performance evaluation of distillation-cum-greenhouse for a warm and humid climate. Desalination. 2000; 128: 67-80.

104.Duffie JA, Beckman WA. Solar engineering of thermal process, 4th Edition. Hoboken: John Wiley\& Sons Inc; 2013. 
105. Kaushal A, Goel V. Solar stills: A review. Renew Sust Energ Rev. 2010; 14: 446-453.

106. Badran AA, Al-Hallaq IA, Eyal Salman IA, Odat MZ. A solar still augmented with a flat-plate collector. Desalination. 2005; 172: 227-234.

107. Arslan M. Experimental investigation of still performance for different active solar still designs under closed cycle mode. Desalination. 2012; 307: 9-19.

108. Abdallah S, Badran O, Abu-Khader MM. Performance evaluation of a modified design of a single slope solar still. Desalination. 2008; 219: 222-230.

109.Voropoulos K, Mathioulakis E, Belessiotis V. Experimental investigation of a solar still coupled with solar collectors. Desalination. 2001; 138: 103-110.

110. Kargarsharifabad H, Ghiasi M, Jahangiri Mamouri S, Shafii MB. A novel integrated solar desalination system with a pulsating heat pipe. Desalination. 2013; 311: 206-210.

111. Kumar S, Dubey A, Tiwari GN. A solar still augmented with an evacuated tube collector in forced mode. Desalination. 2014; 347: 15-24.

112. Chaouchi B, Zrelli A, Gabsi S. Desalination of brackish water by means of a parabolic solar concentrator. Desalination. 2007; 217: 118-126.

113. Abdel-Rehim ZS, Lasheen A. Experimental and theoretical study of a solar desalination system located in Cairo, Egypt. Desalination. 2007; 217: 52-64.

114.Arunkumar T, Denkenberger D, Ahsan A, Jayaprakash R. The augmentation of distillate yield by using concentrator coupled solar still with phase change material. Desalination. 2013; 314: 189192.

115. Tabrizi FF, Sharak AZ. Experimental study of an integrated basin solar still with a sandy heat reservoir. Desalination. 2010; 253: 195-199.

116. Kumar A, Tiwari GN. Use of waste hot water in double slope solar still through heat exchanger. Energy Convers Manag. 1990; 30: 81-89.

117.Velmurugan V, Srithar K. Solar stills integrated with a mini solar pond - analytical simulation and experimental validation. Desalination. 2007; 216: 232-241.

118. Velmurugan V, Pandiarajan S, Guruparan P, Subramanian LH, Prabaharan CD, Srithar K. Integrated performance of stepped and single basin solar stills with mini solar pond. Desalination. 2009; 249: 902-909.

119. El-Sebaii AA, Aboul-Enein S, Ramadan MR, Khallaf AM. Thermal performance of an active single basin solar still (ASBS) coupled to shallow solar pond (SSP). Desalination. 2011; 280: 183-190.

120.Sampathkumar K, Senthilkumar P. Utilization of solar water heater in a single basin solar still an experimental study. Desalination. 2012; 297: 8-19.

121.Abdullah AS. Improving the performance of stepped solar still. Desalination. 2013; 319: 60-65.

122.El-Zahaby AM, Kabeel AE, Bakry Al, El-Agouz SA, Hawam OM. Enhancement of solar still performance using a reciprocating spray feeding system - an experimental approach. Desalination. 2011; 267: 209-216.

123. Ahmed ST. Study of single-effect solar still with an internal condenser. Sol Wind Tech. 1988; 5: 637-643.

124. Fath HE, Hosny HM. Thermal performance of a single-sloped basin still with an inherent builtin additional condenser. Desalination. 2002; 142: 19-27.

125. Belhadj MM, Bouguettaia H, Marif Y, Zerrouki M. Numerical study of a double-slope solar still coupled with capillary film condenser in south Algeria. Energy Convers Manag. 2015; 94: 245252. 
126. Kumar A, Anand JD, Tiwari GN. Transient analysis of a double slope-double basin solar distiller. Energy Convers Manag. 1991; 31: 129-139.

127. Al-Hinai H, Al-Nassri MS, Jubran BA. Parametric investigation of a double-effect solar still in comparison with a single-effect solar still. Desalination. 2002; 150: 75-83.

128. El-Sebaii AA. Thermal performance of a triple-basin solar still. Desalination. 2005; 174: 23-37.

129.Suneja S, Tiwari GN. Optimization of number of effects for higher yield from an inverted absorber solar still using the Runge-Kutta method. Desalination. 1998; 120: 197-209.

130. Madhlopa A, Johnstone CM. Numerical study of a passive solar still with separate condenser. Renew Energ. 2009; 34: 1668-1677.

131. Toyama S, Aragaki T, Murase K, Tsumura K. Simulation of a multieffect solar distillator. Desalination. 1983; 45: 101-108.

132. Bapeshwararao VS, Singh U, Tiwari GN. Transient analysis of double basin solar still. Energy Convers Manag. 1983; 23: 83-90.

133. Cappelletti GM. An experiment with a plastic solar still. Desalination. 2002; 142: 221-227.

134. Rajaseenivasan T, Elango T, Kalidasa Murugavel K. Comparative study of double basin and single basin solar stills. Desalination. 2013; 309: 27-31.

135. Toyama S, Aragaki T, Salah HM, Murase K. Dynamic characteristics of a multistage thermal diffusion type solar distillator. Desalination. 1987; 67: 21-32.

136. Tanaka H. Experimental study of vertical multiple-effect diffusion solar still coupled with a flat plate reflector. Desalination. 2009; 249: 34-40.

137. Kaushal AK, Mittal MK, Gangacharyulu D. An experimental study of floating wick basin type vertical multiple effect diffusion solar still with waste heat recovery. Desalination. 2017; 414: 35-45.

138. Tanaka H, Nosoko T, Nagata T. Parametric investigation of a basin-type-multiple-effect coupled solar still. Desalination. 2000; 130: 295-304.

139. Singh AK, Tiwari GN. Performance study of double effect distillation in a multiwick solar still. Energy Convers Manag. 1992; 33: 207-214.

140.Yeh HM. Experimental studies on upward-type double-effect solar distillers with air flow through the second effect. Energy. 1993; 18: 1107-1111.

141.Dashtban M, Tabrizi FF. Thermal analysis of a weir-type cascade solar still integrated with PCM storage. Desalination. 2011; 279: 415-422.

142. Reddy KS, Kumar KR, O'Donovan TS, Mallick TK. Performance analysis of an evacuated multistage solar water desalination system. Desalination. 2012; 288: 80-92.

143. Ahmed MI, Hrairi M, Ismail AF. On the characteristics of multistage evacuated solar distillation. Renew Energ. 2009; 34: 1471-1478.

144. Mahkamov K, Akhatov JS. Experimental study of the performance of multi-effect solar thermal water desalination system. Appl Sol Energy. 2008; 44: 31-34.

145. Kabeel AE, Omara ZM, Younes MM. Techniques used to improve the performance of the stepped solar still - a review. Renew Sust Energ Rev. 2015; 46: 178-188.

146. Patel MI, Meena PM, Inkia S. Experimental investigation on single slope-double basin active solar still coupled with evacuated glass tubes. Int J Adv Eng Res and Stud. 2011; 1: 4-9.

147.Deshmukh R, Kolhe K. An experimental study on double basin solar still augmented with evacuated tubes and reflector. Int J Curr Eng Technol. 2016; 5: 295-299. 
148. Alaudeen A, Johnson K, Ganasundar P, Syed Abuthahir A, Srithar K. Study on stepped type basin in a solar still. J King Saud Univ Eng Sci. 2014; 26: 176-183.

149. El-Samadony YA, Abdullah AS, Omara ZM. Experimental study of stepped solar still integrated with reflectors and external condenser. Exp Heat Transf. 2015; 28: 392-404.

150. Kumar M, Kumar S, Manchanda H. Design, fabrication and thermal analysis of a stepped solar still with phase change materials. Int J Sci Res Dev. 2016; 4: 890-895.

151. Kumar M, Yadav C, Manchanda H. Thermal performance of a weir-type cascade solar still: An experimental study. Int J Sci Res Dev. 2016; 4: 339-344.

152. Manivel R, Sivakumar S, Rufuss DD. Experimental investigation of solar desalination system with roof heating. Int J Earth Sci Eng. 2014; 7: 1459-1464.

153. Elango T, Murugavel KK. The effect of the water depth on the productivity for single and double basin double slope glass solar stills. Desalination. 2015; 359: 82-91.

154. Velmurugan V, Srithar K. Performance analysis of solar stills based on various factors affecting the productivity - a review. Renew Sust Energ Rev. 2011; 15: 1294-1304.

155. Asadi RZ, Suja F, Ruslan MH, Jalil NA. The application of a solar still in domestic and industrial wastewater treatment. Sol Energy. 2013; 93: 63-71.

156.Sampathkumar K, Arjunan TV, Pitchandi P, Senthilkumar P. Active solar distillation - a detailed review. Renew Sust Energ Rev. 2010; 14: 1503-1526.

157. Muftah AF, Alghoul MA, Fudholi A, Abdul-Majeed MM, Sopian K. Factors affecting basin type solar still productivity: A detailed review. Renew Sust Energ Rev. 2014; 32: 430-447.

158. Yadav S, Sudhakar K. Different domestic designs of solar stills: A review. Renew Sust Energ Rev. 2015; 47: 718-731.

159. Murugavel KK, Sivakumar S, Ahamed JR, Chockalingam KK, Srithar K. Single basin double slope solar still with minimum basin depth and energy storing materials. Appl Energy. 2010; 87: 514523.

160.Zamfir E, Oancea C, Badescu V. Cloud cover influence on long-term performances of flat plate solar collectors. Renew Energ. 1994; 4: 339-347.

161.El-Nashar AM. Seasonal effect of dust deposition on a field of evacuated tube collectors on the performance of a solar desalination plant. Desalination. 2009; 239: 66-81.

162. Hegazy AA. Effect of dust accumulation on solar transmittance through glass covers of platetype collectors. Renew Energ. 2001; 22: 525-540.

163.El-Sebaii AA. On effect of wind speed on passive solar still performance based on inner/outer surface temperatures of the glass cover. Energy. 2011; 36: 4943-4949.

164. Murugavel KK, Anburaj P, Hanson RS, Elango T. Progresses in inclined type solar stills. Renew Sust Energ Rev. 2013; 20: 364-377.

165. El-Sebaii AA. Effect of wind speed on some designs of solar stills. Energy Convers Manag. 2000; 41: 523-538.

166. Arunkumar T, Vinothkumar K, Ahsan A, Jayaprakash R, Kumar S. Experimental study on various solar still designs. Int Math Res Not. 2012; 2012: 1-10.

167. Prakash P, Velmurugan V. Parameters influencing the productivity of solar stills - a review. Renew Sust Energ Rev. 2015; 49: 585-609.

168. Lindblom J, Nordell B. Water production by underground condensation of humid air. Desalination. 2006; 189: 248-260. 
169. Khalifa AJ, Hamood AM. Performance correlations for basin type solar stills. Desalination. 2009; 249: 24-28.

170. Kabeel AE, Khalil A, Omara ZM, Younes MM. Theoretical and experimental parametric study of modified stepped solar still. Desalination. 2012; 289: 12-20.

171.Tripathi R, Tiwari GN. Effect of water depth on internal heat and mass transfer for active solar distillation. Desalination. 2005; 173: 187-200.

172.Samee MA, Mirza UK, Majeed T, Ahmad N. Design and performance of a simple single basin solar still. Renew Sust Energ Rev. 2007; 11: 543-549.

173.Köhl M, Jorgensen G, Brunold S, Carlsson B, Heck M, Möller K. Durability of polymeric glazing materials for solar applications. Sol Energy. 2005; 79: 618-623.

174. Manokar AM, Murugavel KK, Esakkimuthu G. Different parameters affecting the rate of evaporation and condensation on passive solar still - A review. Renew Sust Energ Rev. 2014; 38: 309-322.

175. Tiwari GN, Sinha S, Saxena P, Kumar S. Review of solar distiller in other thermal applications. Int J Sol Energy. 1992; 13: 135-144.

176. Eltawil MA, Zhengming Z. Wind turbine-inclined still collector integration with solar still for brackish water desalination. Desalination. 2009; 249: 490-497.

177.Ahmed HM, Alfaylakawi KA. Productivity enhancement of conventional solar stills using water sprinklers and cooling fan. J Adv Sci Eng Res. 2012; 2: 168-177.

178. Hashim AY, Al-Asadi JM, Taha WA. Experimental investigation of symmetrical double slope single basin solar stills productivity with different Insulation. J Kufa-Physics. 2009; 1: 26-32.

179.Ibrahim AGM, Elshamarka SE. Performance study of a modified basin type solar still. Sol Energy. 2015; 118: 397-409.

180. Tiwari AK, Tiwari GN. Effect of the condensing cover's slope on internal heat and mass transfer in distillation: An indoor simulation. Desalination. 2005; 180: 73-88.

181. Faegh M, Shafii MB. Experimental investigation of a solar still equipped with an external heat storage system using phase change materials and heat pipes. Desalination. 2017; 409: 128-135.

182. Radhwan AM. Transient performance of a stepped solar still withbuilt-in latent heat thermal energy storage. Desalination. 2005; 171: 61-76.

183. Bhattacharyya A. Solar stills for desalination of water in rural households. Int J Environ and Sustain. 2013; 2: 21-30.

184. Malaiyappan P, Elumalai N. Review on application of nonconventional energy source: Solar stills. J Chem Pharm Sci. 2015; 974: 2115.

185. Srivastava PK, Agrawal SK. Experimental and theoretical analysis of single sloped basin type solar still consisting of multiple low thermal inertia floating porous absorbers. Desalination. 2013; 311: 198-205.

186.Sharshir SW, Yang N, Peng G, Kabeel AE. Factors affecting solar stills productivity and improvement techniques: A detailed review. Appl Therm Eng. 2016; 100: 267-284.

187.Patel SG, Bhatnagar S, Vardia J, Ameta SC. Use of photocatalysts in solar desalination. Desalination. 2006; 189: 287-291.

188. Wang Z, Horseman T, Straub AP, Yip NY, Li D, Elimelech M, et al. Pathways and challenges for efficient solar-thermal desalination. Sci Adv. 2019; 5: eaax0763.

189. Velmurugan V, Deenadayalan CK, Vinod H, Srithar K. Desalination of effluent using fin type solar still. Energy. 2008; 33: 1719-1727. 
190.Velmurugan V, Kumar KN, Haq TN, Srithar K. Performance analysis in stepped solar still for effluent desalination. Energy. 2009; 34: 1179-1186.

191. Keshtkar M, Eslami M, Jafarpur K. Effect of design parameters on performance of passive basin solar stills considering instantaneous ambient conditions: A transient CFD modeling. Sol Energy. 2020; 201: 884-907.

192. Cheng WL, Huo YK, Nian YL. Performance of solar still using shape-stabilized PCM: Experimental and theoretical investigation. Desalination. 2019; 455: 89-99.

193. Kabeel AE, El-Maghlany WM, Abdelgaied M, Abdel-Aziz MM. Performance enhancement of pyramid-shaped solar stills using hollow circular fins and phase change materials. J Energy Storage. 2020; 31: 101610.

194. Kantesh DC. Design of solar still using phase changing material as a storage medium. Int J Sci Eng Res. 2012; 3: 1-6.

195. Kabeel AE, Abdelgaied M. Observational study of modified solar still coupled with oil serpentine loop from cylindrical parabolic concentrator and phase changing material under basin. Sol Energy. 2017; 144: 71-78.

196. Sanserwal M, Singh A, Singh P. Impact of materials and economic analysis of single slope single basin passive solar still: A review. Mater Today: Proc. 2020; 21: 1643-1652.

197. Al-harahsheh M, Abu-Arabi M, Mousa H, Alzghoul Z. Solar desalination using solar still enhanced by external solar collector and PCM. Appl Therm Eng. 2018; 128: 1030-1040.

198. Hasnain SM. Review on sustainable thermal energy storage technologies, Part I: Heat storage materials and techniques. Energy Convers and Manag. 1998; 39: 1127-1138.

199. Canbazoglu S, Şahinaslan A, Ekmekyapar A, Aksoy YG, Akarsu F. Enhancement of solar thermal energy storage performance using sodium thiosulfate pentahydrate of a conventional solar water-heating system. Energy Build. 2005; 37: 235-242.

200. Ramasamy S, Sivaraman B. Heat transfer enhancement of solar still using phase change materials (PCMs). Int J Eng Adv Technol. 2013; 2: 597-600.

201.El-Sebaii AA, Al-Ghamdi AA, Al-Hazmi FS, Faidah AS. Thermal performance of a single basin solar still with PCM as a storage medium. Appl Energy. 2009; 86: 1187-1195.

202.Omara ZM, Kabeel AE, Younes MM. Enhancing the stepped solar still performance using internal reflectors. Desalination. 2013; 314: 67-72.

203.Omara ZM, Kabeel AE, Younes MM. Enhancing the stepped solar still performance using internal and external reflectors. Energy Convers Manag. 2014; 78: 876-881.

204. Nassar YF, Yousif SA, Salem AA. The second generation of the solar desalination systems. Desalination. 2007; 209: 177-181.

205. Fathy M, Hassan H, Ahmed MS. Experimental study on the effect of coupling parabolic trough collector with double slope solar still on its performance. Sol Energy. 2018; 163: 54-61.

206. Tanaka H. A theoretical analysis of basin type solar still with flat plate external bottom reflector. Desalination. 2011; 279: 243-251.

207. Tanaka H, Nakatake Y. Theoretical analysis of a basin type solar still with internal and external reflectors. Desalination. 2006; 197: 205-216.

208. Sathyamurthy R, El-Agouz E. Experimental analysis and energy efficiency of a conventional solar still with Fresnel lens and energy storage material. Heat Transf Asian Res. 2019; 48: 885-895. 
209. Sriram V, Kondraganti V, Lokireddy CT, Jeevahan J, Joseph GB, Raj RB, et al. Investigation of effect of the Fresnel lens on the performance of the double slope single basin solar still. Int J Ambient Energy. 2019; 1-6.

210.Johnson A, Mu L, Park YH, Valles DJ, Wang H, Xu P, et al. A Thermal model for predicting the performance of a solar still with fresnel lens. Water. 2019; 11: 1860.

211. Hassan H, Ahmed M, Fathy M. Experimental work on the effect of saline water medium on the performance of solar still with tracked parabolic trough collector (TPTC). Renew Energ. 2019; 135: 136-147.

212.Sommariva C, Hogg H, Callister K. Forty-year design life: The next target material selection and operating conditions in thermal desalination plants. Desalination. 2001; 136: 169-176.

213.Salibi Z. Performance of reinforced thermosetting resin pipe systems in desalination applications: A long-term solution to corrosion-The Arabian Gulf example. Desalination. 2001; 138: 379-384.

214.Garg HP, Mann HS. Effect of climatic, operational and design parameters on the year round performance of single-sloped and double-sloped solar still under Indian arid zone conditions. Sol Energy. 1976; 18: 159-163.

215.Sadhwani JJ, Veza JM, Santana C. Case studies on environmental impact of seawater desalination. Desalination. 2005; 185: 1-8.

216.Von Meerganz GM. "Direct" and socially-induced environmental impacts of desalination. Desalination. 2005; 185: 57-70.

217. Lattemann S, Hopner T. Environmental impact and impact assessment of seawater desalination. Desalination. 2008; 220: 1-15.

218. Ni G, Miljkovic N, Ghasemi H, Huang X, Boriskina SV, Lin CT, et al. Volumetric solar heating of nanofluids for direct vapor generation. Nano Energy. 2015; 17: 290-301.

219. Hota SK, Diaz G. Activated carbon dispersion as absorber for solar water evaporation: A parametric analysis. Sol Energy. 2019; 184: 40-51.

220.Su W, Darkwa J, Kokogiannakis G. Review of solid-liquid phase change materials and their encapsulation technologies. Renew Sust Energ Rev. 2015; 48: 373-391.

221. Tao P, Ni G, Song C, Shang W, Wu J, Zhu J, et al. Solar-driven interfacial evaporation. Nat Energy. 2018; 3: 1031-1041.

222.Lim DK, Barhoumi A, Wylie RG, Reznor G, Langer RS, Kohane DS. Enhanced photothermal effect of plasmonic nanoparticles coated with reduced graphene oxide. Nano Lett. 2013; 13: 40754079.

223. Halas NJ, Lal S, Chang WS, Link S, Nordlander P. Plasmons in strongly coupled metallic nanostructures. Chem Rev. 2011; 111: 3913-3961.

224.Neumann O, Feronti C, Neumann AD, Dong A, Schell K, Lu B, et al. Compact solar autoclave based on steam generation using broadband light-harvesting nanoparticles. Proc Natl Acad Sci. 2013; 110: 11677-11681.

225. Raza A, Lu JY, Alzaim S, Li H, Zhang T. Novel receiver-enhanced solar vapor generation: Review and perspectives. Energies. 2018; 11: 253.

226. Neumann O, Urban AS, Day J, Lal S, Nordlander P, Halas NJ. Solar vapor generation enabled by nanoparticles. ACS Nano. 2013; 7: 42-49.

227. Merabia S, Keblinski P, Joly L, Lewis L, Barrat JL. Critical heat flux around strongly heated nanoparticles. Phys Rev E. 2009; 79: 021404. 
228.Zhao D, Duan H, Yu S, Zhang Y, He J, Quan X, et al. Enhancing localized evaporation through separated light absorbing centers and scattering centers. Sci Rep. 2015; 5: 17276.

229. Hogan NJ, Urban AS, Ayala-Orozco C, Pimpinelli A, Nordlander P, Halas NJ. Nanoparticles heat through light localization. Nano Lett. 2014; 14: 4640-4645.

230. Hou B, Cui Z, Zhu X, liu X, Wang G, Wang J, et al. Functionalized carbon materials for efficient solar steam and electricity generation. Mater Chem Phys. 2019; 222: 159-164.

231. Lapotko D. Optical excitation and detection of vapor bubbles around plasmonic nanoparticles. Opt Express. 2009; 17: 2538-2556.

232.Jin H, Lin G, Bai L, Zeiny A, Wen D. Steam generation in a nanoparticle-based solar receiver. Nano Energy. 2016; 28: 397-406.

233. Amjad M, Raza G, Xin Y, Pervaiz S, Xu J, Du X, et al. Volumetric solar heating and steam generation via gold nanofluids. Appl Energy. 2017; 206: 393-400.

234.Zielinski MS, Choi JW, La Grange T, Modestino M, Hashemi SM, Pu Y, et al. Hollow mesoporous plasmonic nanoshells for enhanced solar vapor generation. Nano Lett. 2016; 16: 2159-2167.

235. Kabeel AE, Omara ZM, Essa FA. Enhancement of modified solar still integrated with external condenser using nanofluids: An experimental approach. Energy Convers Manag. 2014; 78: 493498.

236. Wang J, Li Y, Deng L, Wei N, Weng Y, Dong S, et al. High-performance photothermal conversion of narrow-bandgap $\mathrm{Ti}_{2} \mathrm{O}_{3}$ nanoparticles. Adv Mater. 2017; 29: 1603730.

237. Theye ML, Paret V. Spatial organization of the sp2-hybridized carbon atoms and electronic density of states of hydrogenated amorphous carbon films. Carbon. 2002; 40: 1153-1166.

238. Liu X, Wang X, Hunag J, Cheng G, He Y. Volumetric solar steam generation enhanced by reduced graphene oxide nanofluid. Appl Energy. 2018; 220: 302-312.

239. Hota SK, Diaz G. Activated carbon dispersion as absorber for solar water evaporation: A parametric analysis. Sol Energy. 2019; 184: 40-51.

240.Ulset ET, Kosinski P, Balakin BV. Solar steam in an aqueous carbon black nanofluid. Appl Therm Eng. 2018; 137: 62-65.

241. Hota SK, Diaz G. Enhancing solar water evaporation with activated carbon. MRS Adv. 2020; 5 : 2565-2574.

242. Colombara D, Dale PJ, Kissling GP, Peter LM, Tombolato S. Photoelectrochemical screening of solar cell absorber layers: Electron transfer kinetics and surface stabilization. J Phys Chem C. 2016; 120: 15956-15965.

243. Prieto C, Cabeza LF. Thermal energy storage (TES) with phase change materials (PCM) in solar power plants (CSP). Concept and plant performance. Appl Energy. 2019; 254: 113646.

244. Wang Y, Yang X, Xiong T, Li W, Shah KW. Performance evaluation approach for solar heat storage systems using phase change material. Energy Build. 2017; 155: 115-127.

245.Xiong T, Zheng L, Shah KW. Nano-enhanced phase change materials (NePCMs): A review of numerical simulations. Appl Therm Eng. 2020; 178: 115492.

246.Abu-Arabi M, Al-harahsheh M, Mousa H, Alzghoul Z. Theoretical investigation of solar desalination with solar still having phase change material and connected to a solar collector. Desalination. 2018; 448: 60-68.

247. Shah KW. A review on enhancement of phase change materials-A nanomaterials perspective. Energy Build. 2018; 175: 57-68. 
248. Silakhori M, Naghavi SM, Metselaar SH, Mahlia TM, Fauzi H, Mehrali M. Accelerated thermal cycling test of microencapsulated paraffin wax/polyaniline made by simple preparation method for solar thermal energy storage. Materials. 2013; 6: 1608-1620.

249.Ghiami A, Kianifar A, Aryana K, Edalatpour M. Energy and exergy analysis of a single-pass sequenced array baffled solar air heater with packed bed latent storage unit for nocturnal use. Heat Transfer - Asian Res. 2017; 46: 546-568.

250. Parameshwaran R, Jayavel R, Kalaiselvam S. Study on thermal properties of organic ester phasechange material embedded with silver nanoparticles. J Therm Anal Calorim. 2013; 114: 845-858.

251.Deng Y, Li J, Qian T, Guan W, Li Y, Yin X. Thermal conductivity enhancement of polyethylene glycol/expanded vermiculite shape-stabilized composite phase change materials with silver nanowire for thermal energy storage. Chem Eng J. 2016; 295: 427-435.

252. Kalaiselvam S, Parameshwaran R, Harikrishnan S. Analytical and experimental investigations of nanoparticles embedded phase change materials for cooling application in modern buildings. Renew Energy. 2012; 39: 375-387.

253.Cui W, Yuan Y, Sun L, Cao X, Yang X. Experimental studies on the supercoiling and melting/freezing characteristics of nano-copper/sodium acetate trihydrate composite phase change materials. Renew Energy. 2016; 99: 1029-1037.

254. Rufuss DD, Suganthi L, Iniyan S, Davies PA. Effects of nanoparticle-enhanced phase change material (NPCM) on solar still productivity. J Clean Prod. 2018; 192: 9-29.

255. Yang Y, Luo J, Song G, Liu Y, Tang G. The experimental exploration of nano-Si3N4/paraffin on thermal behavior of phase change materials. Thermochimi Acta. 2014; 597: 101-106.

256. Sharma RK, Ganesan P, Tyagi VV, Metselaar HS, Sandaran SC. Thermal properties and heat storage analysis of palmitic acid- $\mathrm{TiO}_{2}$ composite as nano-enhanced organic phase change material (NEOPCM). Appl Therm Eng. 2016; 99: 1254-1262.

257. Nourani M, Hamdami N, Keramat J, Moheb A, Shahedi M. Thermal behavior of paraffin-nanoAl2O3 stabilized by sodium stearoyl lactylate as a stable phase change material with high thermal conductivity. Renew Energy. 2016; 88: 474-482.

258. Fan LW, Fang X, Wang X, Zeng Y, Xiao YQ, Yu ZT, et al. Effects of various carbon nanofillers on the thermal conductivity and energy storage properties of paraffin-based nanocomposite phase change materials. Appl Energy. 2013; 110: 163-172.

259.Zaib Q, Fath H. Application of carbon nano-materials in desalination processes. Desalination Water Treat. 2013; 51: 627-636.

260.Sarı A, Karaipekli A. Thermal conductivity and latent heat thermal energy storage characteristics of paraffin/expanded graphite composite as phase change material. Appl Therm Eng. 2007; 27: 1271-1277.

261. Mehrali M, Latibari ST, Mehrali M, Metselaar HS, Silakhori M. Shape-stabilized phase change materials with high thermal conductivity based on paraffin/graphene oxide composite. Energy Convers Manag. 2013; 67: 275-282.

262. Wang W, Wang C, Wang T, Li W, Chen L, Zou R, et al. Enhancing the thermal conductivity of neicosane/silica phase change materials by reduced graphene oxide. Mater Chem Phys. 2014; 147: 701-706.

263. Mehrali M, Latibari ST, Mehrali M, Mahlia TM, Metselaar HS. Preparation and properties of highly conductive palmitic acid/graphene oxide composites as thermal energy storage materials. Energy. 2013; 58: 628-634. 
264. Karaipekli A, Biçer A, Sarı A, Tyagi VV. Thermal characteristics of expanded perlite/paraffin composite phase change material with enhanced thermal conductivity using carbon nanotubes. Energy Convers Manag. 2017; 134: 373-381.

265.Li M. A nano-graphite/paraffin phase change material with high thermal conductivity. Appl Energy. 2013; 106: 25-30.

266. Fang X, Fan LW, Ding Q, Wang X, Yao XL, Hou JF, et al. Increased thermal conductivity of eicosane-based composite phase change materials in the presence of graphene nanoplatelets. Energy Fuels. 2013; 27: 4041-4047.

267. Munyalo JM, Zhang X. Particle size effect on thermophysical properties of nanofluid and nanofluid based phase change materials: A review. J Mol Liq. 2018; 265: 77-87.

268. Leong KY, Rahman MR, Gurunathan BA. Nano-enhanced phase change materials: A review of thermo-physical properties, applications and challenges. J Energy Storage. 2019; 21: 18-31.

269.Qu Y, Wang S, Zhou D, Tian Y. Experimental study on thermal conductivity of paraffin-based shape-stabilized phase change material with hybrid carbon nanoadditives. Renew Energy. 2020; 146: 2637-2645.

270.Yadav C, Sahoo RR. Experimental analysis for optimum thermal performance and thermophysical parameters of MWCNT based capric acid PCM by using T-history method. Powder Technol. 2020; 364: 392-403.

271.Du R, Li W, Xiong T, Yang X, Wang Y, Shah KW. Numerical investigation on the melting of nanoparticle-enhanced PCM in latent heat energy storage unit with spiral coil heat exchanger. Build Simul. 2019; 12: 869-879.

272.Zeng Y, Fan LW, Xiao YQ, Yu ZT, Cen KF. An experimental investigation of melting of nanoparticle-enhanced phase change materials (NePCMs) in a bottom-heated vertical cylindrical cavity. Int J Heat Mass Transf. 2013; 66: 111-117.

273. Chiam HW, Azmi WH, Adam NM, Ariffin MK. Numerical study of nanofluid heat transfer for different tube geometries-A comprehensive review on performance. Int Commun Heat Mass Transfer. 2017; 86: 60-70.

274.Zhang P, Li J, Lv L, Zhao Y, Qu L. Vertically aligned graphene sheets membrane for highly efficient solar thermal generation of clean water. ACS Nano. 2017; 11: 5087-5093.

275. Wang Z, Liu Y, Tao P, Shen Q, Yi N, Zhang F, et al. Bio-inspired evaporation through plasmonic film of nanoparticles at the air-water interface. Small. 2014; 10: 3234-3239.

276.Zhu L, Gao M, Peh CK, Ho GW. Solar-driven photothermal nanostructured materials designs and prerequisites for evaporation and catalysis applications. Mater Horizons. 2018; 5: 323-343.

277. Wang P. Emerging investigator series: The rise of nano-enabled photothermal materials for water evaporation and clean water production by sunlight. Environ Sci Nano. 2018; 5: 10781089.

278. Ito Y, Tanabe Y, Han J, Fujita T, Tanigaki K, Chen M. Multifunctional porous graphene for highefficiency steam generation by heat localization. Adv Mater. 2015; 27: 4302-4307.

279. Creutzig F, Agoston P, Goldschmidt JC, Luderer G, Nemet G, Pietzcker RC. The underestimated potential of solar energy to mitigate climate change. Nat Energy. 2017; 2: 17140.

280. Deng Z, Zhou J, Miao L, Liu C, Peng Y, Sun L, et al. The emergence of solar thermal utilization: Solar-driven steam generation. J Mater Chem A. 2017; 5: 7691-7709. 
281. Chen X, Goodnight D, Gao Z, Cavusoglu AH, Sabharwal N, DeLay M, et al. Scaling up nanoscale water-driven energy conversion into evaporation-driven engines and generators. Nat Commun. 2015; 6: 1-7.

282. Wang $Y$, Zhang L, Wang P. Self-floating carbon nanotube membrane on macroporous silica substrate for highly efficient solar-driven interfacial water evaporation. ACS Sustain Chem Eng. 2016; 4: 1223-1230.

283. Yang P, Liu K, Chen Q, Li J, Duan J, Xue G, et al. Solar-driven simultaneous steam production and electricity generation from salinity. Energy Environ Sci. 2017; 10: 1923-1927.

284. Alhosani $\mathrm{MH}$, Zhang T. Dynamics of microscale liquid propagation in micropillar arrays. Langmuir. 2017; 33: 6620-6629.

285. Li X, Xu W, Tang M, Zhou L, Zhu B, Zhu S, et al. Graphene oxide-based efficient and scalable solar desalination under one sun with a confined 2D water path. Proc Natl Acad Sci. 2016; 113: 13953-13958.

286. Li X, Lin R, Ni G, Xu N, Hu X, Zhu B, et al. Three-dimensional artificial transpiration for efficient solar waste-water treatment. Natl Sci Rev. 2018; 5: 70-77.

287.Lu JY, Raza A, Noorulla S, Alketbi AS, Fang NX, Chen G, et al. Near-perfect ultrathin nanocomposite absorber with self-formed topping plasmonic nanoparticles. Adv Opt Mater. 2017; 5: 1700222.

288. Lu JY, Nam SH, Wilke K, Raza A, Lee YE, AlGhaferi A, et al. Localized surface plasmon-enhanced ultrathin film broadband nanoporous absorbers. Adv Opt Mater. 2016; 4: 1255-1264.

289.Zhou L, Tan Y, Wang J, Xu W, Yuan Y, Cai W, et al. 3D self-assembly of aluminium nanoparticles for plasmon-enhanced solar desalination. Nat Photonics. 2016; 10: 393-398.

290.Liu Y, Lou J, Ni M, Song C, Wu J, Dasgupta NP, et al. Bioinspired bifunctional membrane for efficient clean water generation. ACS Appl Mater Interfaces. 2016; 8: 772-779.

291.Shi Y, Li R, Jin Y, Zhuo S, Shi L, Chang J, et al. A 3D photothermal structure toward improved energy efficiency in solar steam generation. Joule. 2018; 2: 1171-1186.

292.Zhuang S, Zhou L, Xu W, Xu N, Hu X, Li X, et al. Tuning transpiration by interfacial solar absorberleaf engineering. Adv Sci. 2018; 5: 1700497.

293.Kashyap V, Al-Bayati A, Sajadi SM, Irajizad P, Wang SH, Ghasemi H. A flexible anti-clogging graphite film for scalable solar desalination by heat localization. J Mater Chem A. 2017; 5: 15227-15234.

294.Yin Z, Wang H, Jian M, Li Y, Xia K, Zhang M, et al. Extremely black vertically aligned carbon nanotube arrays for solar steam generation. ACS Appl Mater Interfaces. 2017; 9: 28596-28603.

295. Dao VD, Choi HS. Carbon-based sunlight absorbers in solar-driven steam generation devices. Glob Chall. 2018; 2: 1700094.

296.Liu Y, Chen J, Guo D, Cao M, Jiang L. Floatable, self-cleaning, and carbon-black-based superhydrophobic gauze for the solar evaporation enhancement at the air-water interface. ACS Appl Mater Interfaces. 2015; 7: 13645-13652.

297. Chandrashekara M, Yadav A. Experimental study of exfoliated graphite solar thermal coating on a receiver with a Scheffler dish and latent heat storage for desalination. Sol Energy. 2017; 151: 129-145.

298. Yang Y, Zhao R, Zhang T, Zhao K, Xiao P, Ma Y, et al. Graphene-based standalone solar energy converter for water desalination and purification. ACS Nano. 2018; 12: 829-835. 
299. Awad FS, Kiriarachchi HD, AbouZeid KM, Özgur U, El-Shall MS. Plasmonic graphene polyurethane nanocomposites for efficient solar water desalination. ACS Appl Energy Mater. 2018; 1: 976-985.

300. Hu X, Xu W, Zhou L, Tan Y, Wang Y, Zhu S, et al. Tailoring graphene oxide-based aerogels for efficient solar steam generation under one sun. Adv Mater. 2017; 29: 1604031.

301. Li Y, Gao T, Yang Z, Chen C, Kuang Y, Song J, et al. Graphene oxide-based evaporator with onedimensional water transport enabling high-efficiency solar desalination. Nano Energy. 2017; 41: 201-209.

302.Wang X, He Y, Cheng G, Shi L, Liu X, Zhu J. Direct vapor generation through localized solar heating via carbon nanotube nanofluid. Energy Convers Manag. 2016; 130: 176-183.

303.Wang G, Fu Y, Guo A, Mei T, Wang J, Li J, et al. Reduced graphene oxide-Polyurethane nanocomposite foam as a reusable photo receiver for efficient solar steam generation. Chem Mater. 2017; 29: 5629-5635.

304.Zhu M, Li Y, Chen G, Jiang F, Yang Z, Luo X, et al. Tree-inspired design for high-efficiency water extraction. Adv Mater. 2017; 29: 1704107.

305.Xu N, Hu X, Xu W, Li X, Zhou L, Zhu S, et al. Mushrooms as efficient solar steam-generation devices. Adv Mater. 2017; 29: 1606762.

306.Song J, Chen C, Zhu S, Zhu M, Dai J, Ray U, et al. Processing bulk natural wood into a highperformance structural material. Nature. 2018; 554: 224-228.

307.Jia C, Li Y, Yang Z, Chen G, Yao Y, Jiang F, et al. Rich mesostructures derived from natural woods for solar steam generation. Joule. 2017; 1: 588-599.

308. Ma S, Chiu CP, Zhu Y, Tang CY, Long H, Qarony W, et al. Recycled waste black polyurethane sponges for solar vapor generation and distillation. Appl Energy. 2017; 206: 63-69.

309. Ren H, Tang M, Guan B, Wang K, Yang J, Wang F, et al. Hierarchical graphene foam for efficient omnidirectional solar-thermal energy conversion. Adv Mater. 2017; 29: 1702590.

310.Günay AA, Kim H, Nagarajan N, Lopez M, Kantharaj R, Alsaati A, et al. Optically transparent thermally insulating silica aerogels for solar thermal insulation. ACS Appl Mater Interfaces. 2018; 10: 12603-12611.

311. Liu Y, Yu S, Feng R, Bernard A, Liu Y, Zhang Y, et al. A bioinspired, reusable, paper-based system for high-performance large-scale evaporation. Adv Mater. 2015; 27: 2768-2774.

312.Jiang Q, Tian L, Liu KK, Tadepalli S, Raliya R, Biswas $P$, et al. Bilayered biofoam for highly efficient solar steam generation. Adv Mater. 2016; 28: 9400-9407.

313.Liu KK, Jiang Q, Tadepalli S, Raliya R, Biswas P, Naik RR, et al. Wood-graphene oxide composite for highly efficient solar steam generation and desalination. ACS Appl Mater Interfaces. 2017; 9: 7675-7681.

314.Chen C, Kuang Y, Hu L. Challenges and opportunities for solar evaporation. Joule. 2019; 3: 683718.

315. Liu H, Chen C, Chen G, Kuang Y, Zhao X, Song J, et al. High-performance solar steam device with layered channels: Artificial tree with a reversed design. Adv Energy Mater. 2018; 8: 1701616.

316.Xue G, Liu K, Chen Q, Yang P, Li J, Ding T, et al. Robust and low-cost flame-treated wood for high-performance solar steam generation. ACS Appl Mater Interfaces. 2017; 9: 15052-15057.

317.Zhang Y, Ravi SK, Vaghasiya JV, Tan SC. A barbeque-analog route to carbonize moldy bread for efficient steam generation. iScience. 2018; 3: 31-39. 
318. Chen C, Song J, Zhu S, Li Y, Kuang Y, Wan J, et al. Scalable and sustainable approach toward highly compressible, anisotropic, lamellar carbon sponge. Chem. 2018; 4: 544-554.

319. Esteves B, Pereira H. Wood modification by heat treatment: A review. BioResources. 2009; 4: 370-404.

320. Fojutowski A, Wróblewska H, Komorowicz M, Kropacz A, Noskowiak A, Pomian I. Changes in the properties of English oak wood (Quercus robur L.) as a result of remaining submerged in Baltic Sea waters for two years. Int Biodeterior Biodegradation. 2014; 86: 122-128.

321. Li T, Liu H, Zhao X, Chen G, Dai J, Pastel G, et al. Scalable and highly efficient mesoporous woodbased solar steam generation device: Localized heat, rapid water transport. Adv Funct Mater. 2018; 28: 1707134.

322.Chen C, Li Y, Song J, Yang Z, Kuang Y, Hitz E, et al. Highly flexible and efficient solar steam generation device. Adv Mater. 2017; 29: 1701756.

323. Liu PF, Miao L, Deng Z, Zhou J, Su H, Sun L, et al. A mimetic transpiration system for record high conversion efficiency in solar steam generator under one-sun. Mater Today Energy. 2018; 8: 166-173.

324.Zhu M, Li Y, Chen F, Zhu X, Dai J, Li Y, et al. Plasmonic wood for high-efficiency solar steam generation. Adv Energy Mater. 2018; 8: 1701028.

325. Ghaffour N, Bundschuh J, Mahmoudi H, Goosen MF. Renewable energy-driven desalination technologies: A comprehensive review on challenges and potential applications of integrated systems. Desalination. 2015; 356: 94-114.

326. Ni G, Zandavi SH, Javid SM, Boriskina SV, Cooper TA, Chen G. A salt rejecting floating solar still for low-cost desalination. Energy Environ Sci. 2018; 11: 1510-1519.

327. Rufuss DD, Kumar VR, Suganthi L, Iniyan S, Davies PA. Techno-economic analysis of solar stills using integrated fuzzy analytical hierarchy process and data envelopment analysis. Sol Energy. 2018; 159: 820-833.

328. Giwa A, Dufour V, Al Marzooqi F, Al Kaabi M, Hasan SW. Brine management methods: Recent innovations and current status. Desalination. 2017; 407: 1-23.

329.Jones E, Qadir M, van Vliet MT, Smakhtin V, Kang SM. The state of desalination and brine production: A global outlook. Sci Total Environ. 2019; 657: 1343-1356.

330.Liu TK, Sheu HY, Tseng CN. Environmental impact assessment of seawater desalination plant under the framework of integrated coastal management. Desalination. 2013; 326: 10-18.

331. Mannan M, Alhaj M, Mabrouk AN, Al-Ghamdi SG. Examining the life-cycle environmental impacts of desalination: A case study in the State of Qatar. Desalination. 2019; 452: 238-246.

332.Zhou J, Chang VW, Fane AG. An improved life cycle impact assessment (LCIA) approach for assessing aquatic eco-toxic impact of brine disposal from seawater desalination plants. Desalination. 2013; 308: 233-241.

333. Alharbi OA, Phillips MR, Williams AT, Gheith AM, Bantan RA, Rasul NM. Desalination impacts on the coastal environment: Ash Shuqayq, Saudi Arabia. Sci Total Environ. 2012; 421: 163-172.

334.Elsaid K, Sayed ET, Abdelkareem MA, Baroutaji A, Olabi AG. Environmental impact of desalination processes: Mitigation and control strategies. Sci Total Environ. 2020; 740: 140125. 
JEPT2020; 2(4), doi:10.21926/jept.2004018

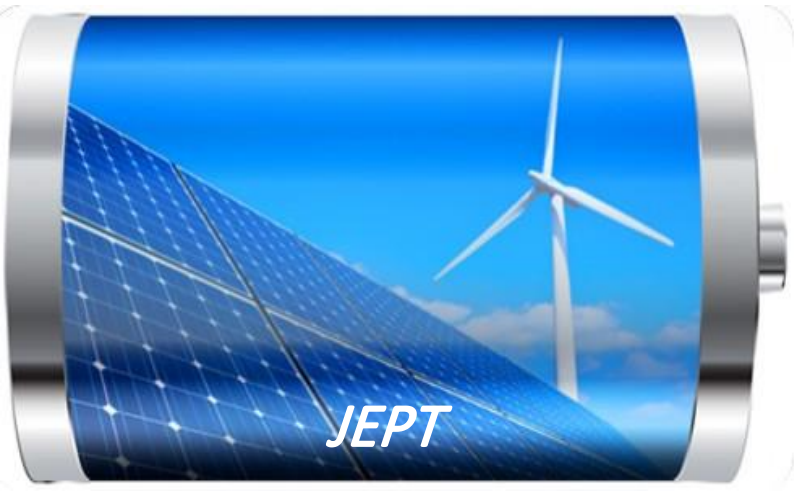

Enjoy JEPTby:

1. Submitting a manuscript

2. Joining in volunteer reviewer bank

3. Joining Editorial Board

4. Guest editing a special issue

For more details, please visit:

http://www.lidsen.com/journal/jept 